\title{
Personality Disorders: Current Scientific Status and Ongoing Controversies
}

\author{
Scott O. Lilienfeld \\ Emory University \\ University of Melbourne \\ Robert D. Latzman \\ Georgia State University
}

Lilienfeld, S. O., \& Latzman, R. D. (2018). Personality disorders: Current scientific status and ongoing controversies. In J.N Butcher (Ed.), APA Handbook of Psychopathology: Psychopathology: Understanding, assessing, and treating adult mental disorders (pp. 557-606). Washington, DC: American Psychological Association. 
Personality Disorders: Scientific Status

For as long as humans have interacted with each other, they have recognized that they differ in personality, and that these differences coalesce into consistent patterns. We are all familiar with what psychologist Harrison Gough (1965) termed "folk concepts": personality traits and constellations of traits that are etched into popular consciousness (see also Tellegen, 1993). One requires no formal psychological training to intuitively grasp such folk concepts as friendliness, dominance, or cautiousness, or to readily identify people who typify them. Gough's insights remind us that many personality traits leave powerful interpersonal residues. Indeed, the term "personality" derives from the Latin "persona," for mask (Teichman, 1985), highlighting the point that personality in part comprises the impressions we form on others. At the same time, this etymology is a potent reminder that discerning others' genuine motives is often far from straightforward, as these motives often lie hidden behind a façade.

For millennia, people have similarly understood that certain folk concepts are associated with marked impairment in everyday life. Greek philosopher Theophrastus (ca. 371-287 B.C.), a follower of Aristotle, penned capsule descriptions of 30 "characters," prototypes of extreme constellations of personality traits that we can identify with little effort even today (Diggle, 2004). For example, for Theophrastus, the "boastful man" "is one who will stand in the bazaar talking to foreigners of the great sums which he has at sea; he will discourse of the vastness of his money-lending business, and the extent of his personal gains and losses." The "distrustful man" "is one who, having sent his slave to market, will send another to ascertain what price he gave. He will carry his money himself, and sit down every two-hundred yards to count it." The "dissimulator" "will praise to their faces those whom he attacked behind their backs...such [are] he doublings and retractions to which [he] will resort. Disingenuous and designing characters are in truth to be shunned more carefully than vipers." It does not take a great stretch of the imagination to identify these three vivid prototypes as bearing marked resemblances to what we would today term narcissistic, paranoid, and psychopathic personality disorders, respectively. 
Personality Disorders: Scientific Status

In contemporary psychology and psychiatry, scholars commonly refer to these and other consistent constellations of traits as personality disorders, especially when they are statistically extreme and tied to distress, impairment, or both. The most recent edition of the Diagnostic and Statistical Manual of Mental Disorders, fifth edition (DSM-5; American Psychiatric Association, 2013), defines a personality disorder as "an enduring pattern of inner experience and behavior that deviates markedly from the expectations of the individual's culture, is pervasive and inflexible, has an onset in adolescence or early adulthood, is stable over time, and leads to distress or impairment" (p. 645).

Personality disorders present us with something of a paradox. On the one hand, many of these conditions, such as those exemplified by Theophrastus' evocative character portraits, are immediately recognizable to most or all of us. Few of us experience any difficulty recognizing marked narcissistic personality disorder traits in a flamboyant politician who talks about himself incessantly and brags at length about his accomplishments. Consistent with these anecdotal impressions, epidemiological data demonstrate that DSM-5 personality disorders are surprisingly common even in general population samples. For example, across six sites (four in the U.S., one in the U.K., and one in Norway), the median prevalence of "any PD [personality disorder" in the community was estimated to be $10.56 \%$ (Lenzenweger, 2008), indicating that approximately one in 10 persons in the general population meets criteria for one or more DSM personality disorders. For reasons that are not clear, the overall prevalence of personality disorders tends to be higher in North and South America than in Europe (Tyrer, Reed, \& Crawford, 2015). At the same time, as we will discuss later (see the "Trait models"), the very concept of "prevalence" is of dubious relevance to personality disorders given that there is weak evidence that many, if any, of these conditions differ qualitatively from normality (Frances, 1993; Haslam, Holland, \& Kuppens, 2012; Trull \& Durrett, 2005; Wiidger, 1993).

On the other hand, despite their ubiquity in the general population, personality disorders are arguably the most poorly understood and most controversial conditions in all of 
Personality Disorders: Scientific Status psychopathology (Clark, 2007; Grove \& Tellegen, 1991). Personality disorders also comprise the most recurrently contentious section of the diagnostic manual (Samuel, Suzuki, \& Griffin, in press). With each successive revision of the DSM, fierce disagreements routinely erupt concerning which personality disorders to include or exclude within the manual, as well as how best to operationalize these disorders to begin with. An inspection of the DSM- 5 definition in the preceding paragraph helps to explain why. What makes a pattern "enduring"? How can we ascertain another person's "inner experience"? What constitutes a "marked deviation"? How "pervasive" and "inflexible" does this pattern need to be? How "stable" over time? How much "distress" or "impairment” must be present (Fowler, O'Donohue, \& Lilienfeld, 2007)? The challenges posed by these questions, although perhaps not insurmountable, are formidable.

The notion of open concepts (Meehl, 1990; Pap, 1953) is relevant here. Open concepts are characterized by three features: (1) fuzzy boundaries, (2) a list of indicators that can be extended indefinitely, and (3) an unclear inner nature. All psychological disorders are open concepts, so what makes personality disorders distinctive? One can legitimately contend that the level of ambiguity characterizing personality disorders is virtually unrivaled in the psychopathology domain. Most, if not all, personality disorders can be thought of as "wide open concepts" in that that their boundaries are especially fuzzy, their indicators (signs and symptoms) are perennial matters of contention, and their etiologies (causes) are largely or entirely unknown.

Despite this conceptual murkiness, it is undeniable that personality disorders matter. For example, data from the U.K. (comparable data from North America are at present unavailable) indicate that the life expectancy of individuals with one or more personality disorders is 19 years shorter for women and 18 years shorter for men (Tyrer \& Reed, 2015). The mediators of this striking difference are unknown, although are likely to in part reflect elevated rates of suicide, as well as poorer health practices (e.g., diet and exercise patterns), higher rates of substance misuse, and violence, among personality disordered individuals (Bogg \& Roberts, 2004). 
Personality Disorders: Scientific Status Although the extent to which such associations are directly causal is unclear - as we will later discover, individuals with personality disorders are also at heightened risk for numerous other psychological conditions - such data demonstrate that personality disorders are predictively useful. Personality disorders also hold important implications for treatment response. For example, co-occurring personality disorders double the risk of poor long-term outcome among patients with clinical depression who have received either psychological or pharmacological interventions (Newton-Howes, Tyrer, \& Johnson, 2006). Furthermore, personality disorders are associated with high rates of premature dropout in psychotherapy (McFarland \& Klein, 2005).

In this chapter, we examine the best available clinical psychological science bearing on personality disorders, with a particular emphasis on longstanding controversies and unresolved conceptual and methodological issues. In doing so, we aim to be provocative. Much of the personality disorders field, we contend, has been characterized by an uncritical acceptance of the DSM personality disorder taxonomy, as well as by an insufficient incorporation of findings from basic personality psychology (see also Widiger \& Costa, 1994; Clark, 2007; Widiger et al., 2009), interpersonal theory, and other disciplines. As a consequence, this field has often not benefited sufficiently from hard-won insights derived from basic psychological science. The great German psychologist Hermann Ebbinghaus (1902) famously described psychology as having a "long past, but a short history." By that, he meant that the subject of matter of psychology has preoccupied people's thinking for centuries, if not millennia, yet as a mature field of inquiry, psychology is relatively young. The same may be said of the personality disorders field.

\section{Historical Milestones}

Theophrastus was merely the first major figure to attempt to offer a systematic classification system for personality disorders. As Livesley (2000) observed, the history of personality disorders can be roughly subdivided into three phrases: (1) the pre-DSM-III phrase, which dates from the 19th century through the first two DSMs, which were published in 1952 and 
Personality Disorders: Scientific Status

1968, respectively, (2) the DSM-III phase, which dates from the publication of DSM-III in 1980 and extends through the relatively minor modifications of DSM-III through DSM-5, and (3) the post-DSM phase, which is reflected, at least in part, by Section III of DSM-5. We survey each of these three phases in broad brush, with a particular focus on the second given its overweening influence on contemporary personality disorders research (see also Crocq, 2013, for a succinct and user-friendly review).

\section{The pre DSM-III phase}

In 19th century Europe, the concept of personality disorders began to take root in the influential writings of several prominent German thinkers, most notably Emil Kraepelin, Ernest Kretschmer, and Kurt Schneider. Although their personality typologies have long been obsolete, their conceptions anticipated a number of subsequent models of personality pathology.

The early German theorists

Kraepelin (1907) conceptualized personality disorders not as distinct conditions in their own right, but instead as typical or mild manifestations - formes frustes (Lilienfeld, Smith, \& Watts, 2016) - of major mental disorders, such as schizophrenia. Kraepelin's theorizing presaged later behavior-genetic data suggesting that schizotypal personality disorder and perhaps some other personality disorders, such as paranoid personality disorder, are attenuated variants of schizophrenia (Raine, 2006). Kretschmer (1925) extended Kraepelin's writings by positing a continuum stretching from schizothymia to schizoidia to schizophrenia (see Livesley, 2001), a view echoed influentially by the brilliant American clinical psychologist Paul Meehl (1962). In the eight edition of his influential textbook, Kraepelin (1915) delineated 7 subtypes of pathological personality: (a) the excitable, (b) the unstable, (c) the impulse-driven, (d) the eccentric, (e) liars and swindlers, (f) antisocial/criminal, and (g) quarrelsome. Although most of Kraepelin's subtypes do not map on unambiguously to DSM personality disorder categories (Crocq, 2013), there are intriguing domains of intersection. For example, the excitable subtype bears similarities to DSM borderline personality disorder, and the eccentric 
Personality Disorders: Scientific Status

subtype bears similarities to DSM schizotypal personality. The liar and swindler subtype, marked by glibness, superficial charm, and deceitful, is reminiscent of Cleckley's (1941) psychopathic personality, a condition that overlaps partly with the more maladaptive DSM diagnosis of antisocial personality disorder (Lilienfeld, 1994).

In another classic volume, Schneider (1923) distinguished abnormal from normal personality, conceptualizing the former as merely more extreme than the latter (Kendell, 2002; Livesley, 2001). In this respect, he foreshadowed trait-based, dimensional models of personality disorder (see "Trait Models"). Within the broad group of individuals with abnormal personality, Schneider demarcated a subgroup that he termed "psychopathic personalities," who "either suffer personally because of their abnormality or make a community suffer because of it" (p. 3). In doing so, he anticipated the concepts of distress and impairment, respectively, in the modern DSM (American Psychiatric Association, 2013). Schneider's use of the term "psychopathic personality," it should be noted, was far more expansive than the typical use today, which refers to a specific personality disorder marked by superficial charm, grandiosity, callousness, guiltlessness, dishonesty, and poor impulse control (Hare, 1991/2003). Within this heterogeneous class, Schneider described 10 subforms: asthenic (easily fatigued), weak-willed, hyperthymic, depressive, insecure, fanatical, attention-seeking, labile, explosive, and affectionless. Some of Schneider's subforms bear similarities to the DSM disorders: for example, his attention-seeking and labile subforms are reminiscent of, and overlap empirically with, histrionic and borderline personality disorder, respectively (Standage, 1979).

\section{Psychoanalytic writers and character disorder}

In the early $20_{\text {th }}$ century, the notion of "character disorders" became influential in psychoanalytic circles (McNeal, 2003). In the eyes of Freudian and neo-Freudian thinkers, such conditions overlapped with many of those that we would today term personality disorders, although they were restricted largely to conditions marked by unethically questionable or at least interpersonally noxious behavior and an apparent absence of insight into such behavior. In 
Personality Disorders: Scientific Status keeping with this emphasis, these psychoanalysts took particular interest in what were later to be recognized as borderline and narcissistic personality disorders. As discussed later in the chapter, in the mid to late 20 th century, such influential psychoanalytic thinkers as Otto Kernberg (1967) and Heinz Kohut (1966) became especially interested in the etiologies of borderline and narcissistic character disorders, tracing their origins to early aberrations in parenting.

The emergence of the DSM

As of the mid-20th century, the classification of personality disorders was haphazard, with scant consensus regarding how to divide the large pie of abnormal personality into psychologically meaningful slices. This state of taxonomic disarray begin to dissipate with the emergence of the DSM. DSM-I, published by the American Psychiatric Association in 1952, was shaped in part by psychoanalytic conceptualizations, such as defense mechanisms (but see Cooper \& Blashfield, 2016, who contend that the influence of psychoanalysis on DSM-I has long been overestimated), and by the writings of The Johns Hopkins University psychiatrist Adolph Meyer, who embraced a biopsychosocial model of psychopathology that regarded mental disorders as reflecting interactions between innate vulnerabilities and unhealthy reactions to life stressors (Double, 1990). Consistent with its largely Meyerian perspective on psychopathology, DSM-I conceptualized many or most personality disorders as pathological reactions to adverse environmental circumstances.

DSM-l's brief (five page) section on personality disorders contained three sections, Personality pattern disturbance, Personality trait disturbance, and Sociopathic personality disturbance. Personality pattern disturbance comprised four conditions: schizoid, paranoid, cyclothymic, and inadequate personalities. Only two of these (schizoid and paranoid) survive as personality disorders today, although cyclothymic personality, now termed cyclothymic disorder, remains in DSM-5 as a mood disorder. The diagnosis of "inadequate personality, "characterized by inadaptability, poor judgment, lack of physical and emotional stamina, and social incompatibility" (p. 35), no longer in the diagnostic system, soon became a convenient target for 
Personality Disorders: Scientific Status

satire and derision. Personality trait disturbance comprised emotionality unstable personality, passive-aggressive-personality, and compulsive personality; the first appears to overlap with DSM-5 histrionic and borderline personality disorders and third with DSM-5 obsessivecompulsive personality disorder, whereas passive-aggressive personality is no longer in the diagnostic manual. Finally, sociopathic personality disturbance comprised antisocial reaction (similar to the Cleckley concept of psychopathy), dissocial reaction (chronic antisocial and criminal behavior stemming from exposure to a dysfunctional environment), sexual reaction, and addiction, the latter subdivided into alcoholism and drug addiction.

Using what has come to be known as a "prototype" approach to diagnosis (Westen \& Shedler, 2000) DSM-I featured brief, paragraph-length, descriptions of all mental disorders, including personality disorders. For example, DSM-I described the diagnosis of "paranoid personality" as follows: "Such individuals are characterized by many traits of the schizoid personality, coupled with an exquisite sensitivity to interpersonal relations, and with a conspicuous tendency to utilize a projection mechanism, expressed by suspiciousness, envy, extreme jealousy and stubbornness" (p. 36). Note the brevity of the description, as well as the now amusingly antiquated invocation of the Freudian defense mechanism of projection. Needless to say, these brief descriptions, reminiscent in some ways of those of Theophrastus, necessitated highly impressionistic, global judgments on the part of practitioners. DSM-I afforded diagnosticians no explicit guidance regarding how many, or which, of the described features needed to be present, nor how pathological (extreme), pervasive, or persistent they needed to be to quality for each diagnosis.

Despite these problems, some authors continue to advocate for a prototype approach to personality disorder diagnosis on the grounds that it accords well with how clinicians think about personality disorders (Shedler et al., 2010). Nevertheless, as we discuss later, this approach is unlikely to be effective for most, and arguably any, DSM personality disorders given that many of them are highly heterogeneous symptomatically. For phenotypically heterogeneous 
Personality Disorders: Scientific Status

disorders, a medium rating on a prototype scale is ambiguous and therefore difficult to interpret, as it can reflect moderate scores on most or all items or high ratings on only one or two items. Moreover, there are serious questions regarding the inter-rater reliability of the prototype approach (Zimmernan, 2011), perhaps reflecting the fact that this approach requires diagnosticians to rely on highly subjective, Gestalt judgments of similarity.

DSM-II, published in 1968, was broadly comparable to DSM-I in its coverage of personality disorders and its use of brief prototype-based descriptions, although it introduced several largely cosmetic changes. All of its 10 personality disorders were consolidated into a single category, with most of the conditions from DSM-I (schizoid, paranoid, cyclothymic, inadequate, antisocial, compulsive) retained, albeit some in renamed form (antisocial was renamed "antisocial personality" and compulsive was renamed "obsessive-compulsive personality"). In addition, emotionally unstable personality was replaced by hysterical (histrionic) personality, and explosive and asthenic personality (marked by fatigability and weakness) were added. Explosive personality was eventually to transmogrify into intermittent explosive disorder, now listed in DSM-5 as an impulse control disorder (Coccaro, 2015), whereas asthenic personality vanished entirely.

\section{The DSM-III phase}

By providing consensual descriptions of personality disorders, DSM-I and DSM-II facilitated the diagnosis of, and research on, these conditions. It was not until DSM-III (American Psychiatric Association, 1980), however, that the concept of personality disorders firmly took hold within clinical psychology and psychiatry, as these conditions were for the first time accorded special prominence in the manual. Because DSM-III "set the mold" for all later editions of the manual as of this writing (DSM-III-R, DSM-IV, DSM-5), we describe its coverage of personality disorders in some detail. 
The multiaxial system

Under the leadership of psychiatrist Robert Spitzer, DSM-III introduced a multiaxial system, in which pathology was described along five dimensions, or axes, of dysfunction. Axis I consisted of major mental disorders, such as schizophrenia, major depression, bipolar disorder, panic disorder, and obsessive-compulsive disorder, whereas Axis II consisted of personality disorders, along with mental retardation (now termed intellectual disability). The primary rationale for the Axis I-Axis II distinction was to distinguish relatively stable vulnerabilities for mental disorders (Axis II) from more transient exacerbations of these vulnerabilities (Spitzer, Williams, \& Skodol, 1980). In more colloquial terms, Axis I disorders ostensibly denote what a person has, whereas Axis II disorders denote what a person is (Triebwasser, Chemerinski, Roussos, \& Siever, 2013); as we discuss later, however (see "DSM-5"), this neat and tidy distinction was beset by several troubling anomalies and has since been discarded.

By providing personality disorders with their own axis (albeit one shared with mental retardation), DSM-III brought heightened attention to personality disorders as a clinical and research focus. Surprisingly, however, analyses suggest that despite what some authors have maintained (Shea, 1995), personality disorder research did not experience a massive postDSM-III boom. Instead, only three personality disorders underwent marked growth in the wake of DSM-III: borderline, antisocial, and schizotypal (Blashfield \& Intoccia, 2000). DSM criteria for personality disorders

As it did for all mental disorders, DSM-III abandoned the prototype approach of the previous two DSMs, largely in response to concerns that the high levels of diagnostician subjectivity inherent to this approach fostered low inter-rater reliability (Tyrer \& Ferguson, 1997). Instead, DSM-III moved to diagnose personality disorders, along with other mental disorders, using sets of standardized diagnostic criteria and algorithms (decision-rules), both of which were designed to enhance agreement among raters. 
Personality Disorders: Scientific Status

The DSM-III criteria were largely monothetic for certain personality disorders, but largely polythetic for others, although the reasons for these differences in criterion format across disorders were not entirely clear. In monothetic criterion sets, diagnostic criteria are necessary, sufficient, or both, to establish a diagnosis (Lilienfeld et al., 2016). For example, for the diagnosis of schizoid personality disorder, DSM-III mandated that the individual meet each of four major criteria: (a) emotional coldness/aloofness, (b) indifference to praise or criticism, (c) an absence of multiple close friendships, and (d) an absence of eccentric behavior (an exclusion criterion). In contrast, in polythetic criterion sets, diagnostic criteria are neither necessary nor sufficient to establish a diagnosis. For example, for the diagnosis of schizotypal personality disorder, DSM-III required that the individual meet any 4 of 8 criteria. Still other criterion sets were a complex mix of monothetic and polythetic criteria, a model sometimes derided as the "Chinese menu approach" to diagnosis. For example, for the diagnosis of histrionic personality disorder, DSM-III required 3 of 5 criteria for one superordinate criterion (dramatic, reactive, and intensely expressed behavior) and 2 of 5 criteria for a second superordinate criterion (disturbances in interpersonal relationships).

A potential advantage of monothetic diagnostic criterion sets is that the resulting diagnoses tend to be relatively homogeneous, at least at the level of signs (observable indicators of a disorder) and symptoms (subjective indicators of a disorder that can only be reported by patients themselves). A potential disadvantage of such criterion sets, however, is that they tend to be associated with low inter-rater reliability (Widiger \& Frances, 1985) given that disagreement regarding only a single criterion will automatically lead to disagreement regarding the diagnosis. Returning to the DSM-III diagnosis of schizoid personality disorder, were two diagnosticians to agree on the presence or absence of 3 of the 4 central criteria yet disagree on only 1 of the 4 criteria, they would necessarily disagree on the presence or absence of the diagnosis. In contrast, polythetic criterion sets tend to be associated with higher inter-rater reliability, because two diagnosticians can disagree on the presence or absence of one or a few 
Personality Disorders: Scientific Status

criteria, yet often still agree on the presence or absence of the disorder. Nevertheless, polythetic criterion sets have the potential disadvantage of inducing considerable heterogeneity at the sign and symptom level (see "Phenotypic heterogeneity").

\section{The DSM personality disorders}

DSM-III distinguished among three clusters of personality disorders: Cluster A (odd, eccentric), which overlapped at least partly with schizophrenia spectrum disorders (Kendler, Neale, \& Walsh, 1995); Cluster B (dramatic, emotional), which overlapped largely with the older psychanalytic category of character disorders; and Cluster C (anxious, fearful), at least some of which appeared to be formes frustes of anxiety disorders. The derivation of these clusters was based largely or entirely on face validity, and hence was far less than ideal. Later factor analytic and cluster analytic data have not consistently recaptured these three posited clusters (Klonsky, 2000; Trull, Verges, Wood, \& Sher, 2013; Tyrer et al., 2015; Widiger \& Costa, 1994).

Nevertheless, probably because of a combination of historical inertia and a reluctance to depart from tradition, these three clusters survive intact in DSM-5 today.

DSM-III contained 11 personality disorders, some of which were holdouts from DSM-II, but some of which were novel. These 11 conditions were schizotypal, schizoid, and paranoid (Cluster A), antisocial, narcissistic, borderline, and histrionic (Cluster B), and avoidant, dependent, compulsive, and passive-aggressive (Cluster C). With the exception of passiveaggressive personality disorder, all of the personality disorders survive in the contemporary diagnostic system, although not without their vocal critics. We describe the features and demographic correlates of each of these conditions in more depth later in the chapter (see "The DSM-5 Personality Disorders: A Capsule Summary").

\section{DSM-III-R and DSM-IV}

The DSM-III-R (American Psychiatric Association, 1987) personality disorders section was broadly similar to that of DSM-III with one notable exception: with the exception of antisocial personality, which required a history of conduct disorder in childhood or adolescence 
Personality Disorders: Scientific Status

was thereby partly monothetic, this section transitioned entirely to polythetic criteria (Widiger, Frances, Spitzer, \& Williams, 1988). DSM-III-R also reduced the amount of criterion overlap between conditions (such as between borderline and histrionic personality disorders) in an effort to improve discriminant validity and aimed to reduce the degree of subjective clinical inference for many criteria. In addition, DSM-III-R placed two provisional personality disorders, sadistic personality disorder (characterized by intentionally cruel behavior toward others) and selfdefeating (masochistic) personality disorder (characterized by behaviors that consistently undermine one's success) in an Appendix to encourage further research.

In keeping with the conservative approach advocated by its chairperson, psychiatrist Allen Frances (see Frances \& Widiger, 2012), DSM-IV (American Psychiatric Association, 2000) introduced few changes, although it demoted passive-aggressive personality disorder to an Appendix in view of its weak scientific evidence base, most notably a paucity of data demonstrating that it is cross-situationally consistent as opposed to a transient response to specific situations (but see Wetzler \& Morey, 1999, for a critique of this decision). Both sadistic and self-defeating personality disorders were dropped from the manual entirely in light of concerns regarding their discriminant validity from other personality disorders; for example, data suggested substantial overlap between sadistic and antisocial personality disorders (Widiger, 1995). At the encouragement of psychodynamic writers, a new condition - depressive personality disorder, which encompasses a pattern of low-level depressive cognitions and behaviors - was added to the Appendix but was not promoted to the full manual in light of concerns regarding its extensive overlap with dysthymic disorder (Morey, Hopwood, \& Klein, 2007).

Despite instituting few changes, Frances (1993) openly recognized many of the limitations with the categorical model of personality disorders of the manual, noting that with regard to dimensional diagnosis of personality, its is a matter of "not whether, but when and 
Personality Disorders: Scientific Status

which." Indeed, he described the DSM categorical diagnoses as "an inherently futile attempt to type a continuum that is without clear boundaries (Frances, p. 110)."

\section{DSM-5}

At long last, we arrive at our present system, namely, DSM-5. The long and lurid history of the DSM-5 personality disorders section has been recounted in numerous sources (e.g., Zachar, Krueger, \& Kendler, 2016) and will be reprised only briefly here. In short, encouraged by the chairpersons of the DSM-5 task force, David Kupfer and Darrel Regier, to think broadly and to consider novel paradigms (Whooley, 2014), the DSM-5 Personality and Personality Disorders (PAPD) task force, an important name change for this workgroup intended to highlight the importance of trait models of personality within personality pathology, initially discussed abandoning the traditional DSM personality disorder categories and instead substituting them with a prototype-approach (Westen Shedler, \& Bradley, 2006) similar to that of DSM-I and DSMII. In this approach diagnosticians would be provided with brief descriptions of each diagnosis and asked to rate each patient's similarity to the prototype on a Likert-type scale. Nevertheless, in view of the aforementioned concerns regarding the inter-rater reliability and construct validity of the prototype approach (Zimmerman, 2011), this proposal was rejected.

The PAPD also considered substituting a trait-based dimensional proposal based largely on meta-analyses of trait terms (e.g., Samuel \& Widiger, 2009). This proposal also accorded broadly with the influential five-factor model of personality (FFM; McCrae \& Costa, 1987) as well as with the Personality-Psychopathology Five (PSY-5), an allied personality taxonomy that incorporates a dimension tied explicitly to psychotic ideation (Harkness, McNulty, \& Ben-Porath, 1995). A dimensional model is consonant with growing evidence, already discussed, that most forms of personality fall along a continuum with normality and hence should not be accommodated within a categorical model (Haslam et al., 2012; Widiger, 1993), an assertion espoused by Allen Frances even as the DSM-IV was being published (Frances, 1993). 
Personality Disorders: Scientific Status

Nevertheless, in light of resistance to a purely trait-based approach (e.g., Shedler et al., 2010), the PAPD eventually converged on a proposed hybrid approach (Oldham, 2015; Skodol, 2012). In this approach, six personality disorders that had received adequate substantiation in research - schizotypal, antisocial, borderline, narcissistic, avoidant, and obsessive-compulsive - were retained, and four others - schizoid, paranoid, histrionic, and avoidant - were slated for the chopping block (narcissistic personality disorder was initially also slated for removal, but was reinstituted in response to arguments from numerous personality disorder scholars; e.g., Miller, Widiger, \& Campbell, 2010). In this rather complex (and some have argued, cumbersome) scheme, clinicians would first ascertain the presence or absence of the higher-order category of personality disorder using two criteria: (1) impairment in sense of self, interpersonal functioning, or both and (2) the presence of pathological traits. Then, to place the individual into one or more of the 6 personality disorder categories, clinicians would rate him or her on a series of (facets) drawn from one or more of five well-established personality disorder dimensions, namely, Negative Affectivity, Detachment, Antagonism, Disinhibition, and Psychoticism. For example, borderline personality disorder was to be marked by extreme scores on four facets drawn from Negative Affectivity (emotional lability, anxiousness, separation insecurity, and depressivity), two facets drawn from Disinhibition (impulsivity and risk-taking), and one facet drawn from Antagonism (hostility). DSM-5 also provided a seventh category of "Personality Disorder-Trait Specified" (PD-TS) for individuals who meet the two overarching criteria for a personality disorder but who do not fit neatly into any of the extant personality disorder categories.

Nevertheless, because it was considered to be too preliminary for widespread clinical or research use, this alternative model was vetoed at the $11_{\text {th }}$ hour by the American Psychiatric Association Board of Trustees and relegated to Section III of the manual ("Emerging Measures and Models"), which is devoted to provisional proposals in need of further research. This decision, although disappointing given that the proposed system is more closely aligned with scientific evidence than is the DSM model, was defensible given that the harms (e.g., erroneous 
Personality Disorders: Scientific Status diagnoses) of radical and untested changes to diagnostic systems often outweigh their benefits (Frances \& Widiger, 2012). Hence, despite years of work, the efforts of the PAPD were ultimately of little avail. Remarkably, the DSM-5 personality disorders section more or less mirrors the DSM-IV personality disorders section verbatim with respect to the included disorders and their associated diagnostic criteria, with the only nontrivial revisions to the section being to the accompanying text.

At the same time, the status of personality disorders in DSM-5 did bear witness to two noteworthy changes. First, DSM-5 eliminated the Appendix disorders entirely, dashing the hopes of those who had wishes for a resurgence of research interest in passive-aggressive and depressive personality disorders. Second, and more importantly, DSM-5 dropped the multiaxial system, abolishing the largely artificial differentiation between personality disorders and other mental disorders. From the outset, the distinction Axis I-Axis II distinction was fraught with scientific contradictions (Clark, 2005a; Harkness \& Lilienfeld, 1997). For one thing, since the publication of DSM-III in 1980, evidence had steadily accumulated that many Axis I conditions, such as major depression and social anxiety disorder (social phobia), are every bit as much disorders of personality as are Axis II conditions. Indeed, analyses demonstrate that most Axis I conditions are as highly correlated with personality traits, such as neuroticism and antagonism (low agreeableness), as are personality disorders (Clark, 2005a, 2007). Moreover, the Axis IAxis II distinction contributed to several bewildering inconsistencies (Frances, 1980). For example, for reasons that were never clearly articulated, schizotypal personality disorder, which data suggest is an attenuated form of schizophrenia (Kendler et al., 1995), was placed on Axis I, whereas cyclothymic disorder (cyclothymia), which data suggest is an attenuated form of bipolar disorder (Kelsoe, 2003), was placed on Axis II. Moreover, there is compelling evidence that many Axis I conditions, such as schizophrenia and generalized anxiety disorder, are just as stable over time as are most Axis II conditions (e.g., Reichenberg, Rieckmann, \& Harvey, 2005). 
Personality Disorders: Scientific Status

For all of these reasons, and more, the decision to eliminate the distinction between Axis I and Axis II was well-advised.

To the bottom line: despite high hopes and valiant efforts on the part of the PAPD to enact large-scale changes, the scientific status of the DSM- 5 can most charitably be considered a disappointment. Despite concerted efforts to at long last place the DSM personality disorders section on firmer scientific footing, the current taxonomy of personality disorders has sadly changed relatively little over the past three and a half decades. At the same time, all is not lost. The inclusion of a personality trait approach in Section III of the manual is a hopeful scientific sign, as it raises the possibility that this model - or more likely, some variant thereof - will supplant or at least supplement the extant personality disorder categories in future versions of the manual. Indeed, the past several years have born witness to dozens of promising studies on the Section III Alternative Model (e.g., Krueger \& Markon, 2014; Few et al., 2013; Morey, Benson, \& Skodol, 2016). Some of this work is already pointing to superior validity of the Alternative Model relative to the extant model. For example, emerging data demonstrate that the Section III criteria for antisocial personality disorder outperform the standard text criteria for this disorder in predicting research-based diagnoses of psychopathy, the condition that antisocial personality disorder was ostensibly intended to operationalize (Wygant et al., 2016).

The development of structured psychiatric interviews

Because of their adoption of explicit diagnostic criteria and algorithms, DSM-III and its successors facilitated a landmark methodological development: the development of structured psychiatric interviews for mental disorders, including personality disorders (Widiger \& Frances, 1987). In reality, most of these interviews are misnamed, as they are better conceptualized as semi-structured interviews given that they afford interviewers considerable leeway in asking follow-up questions. These interviews consist of standardized questions for each DSM criterion followed by recommended probe questions, along with systematic scoring metrics for each criterion. As a consequence, these interviews allow for reasonably systematic determinations of 
Personality Disorders: Scientific Status

DSM personality disorder diagnoses rather than impressionistic global judgments. In this way, structured interviews have enhanced the inter-rater reliability of personality disorder diagnosis (Garb, 1998), although considerable room for improvement remains (see "The dilemma of Interrater reliability"). Structured interviews are especially crucial in view of evidence that many clinicians neglect the DSM criteria when making personality disorder diagnoses in actual practice (Blashfield \& Herkov, 1996; Morey \& Benson, 2016; Morey \& Ochoa, 1989). Furthermore, data indicate that structured interviews of personality disorders outperform unstructured interviews in predicting long-term psychosocial functioning (Samuel et al., 2013).

The most widely used structured interviews for the assessment of personality disorders are the Structured Clinical Interview for DSM-5 Personality Disorders (SCID-5-PD; First, Williams, Benjamin, \& Spitzer, 2015), International Personality Disorders Exam (IPDE; Loranger, Janca, \& Sartorius, 1997), Diagnostic Interview for DSM Personality Disorders (DIPD; Zanarini et al., 2009), and Structured Interview for DSM-IV Personality (SIDP-IV; Pfohl, Blum, \& Zimmerman, 1987). All of these measures display adequate psychometric properties, including inter-rater reliability and construct validity, although they differ somewhat in format. For example, whereas the SCID-5-PD and IPDE arrange questions by diagnosis, the SIDP-IV arranges them by topical domains (e.g., interpersonal relations, self-concept), which may render this interview less susceptible than other interviews to interviewer response styles (Widiger \& Frances, 1987), especially logical errors (the tendency for raters to erroneously assume that items belonging to the same conceptual category should be rated similarly; Newcomb, 1931). In addition, more in-depth structured interviews are available for specific personality disorders, probably the most widely used being the Diagnostic Interview for Borderline-Revised (DIB-R; Zanarini, Gunderson, Frankenburg, \& Chauncey, 198) and the Psychopathy Checklist-Revised (PCL-R; Hare, 1991/2003).

ICD-10 and 11 
Personality Disorders: Scientific Status

Although the DSM, published by the American Psychiatric Association and used widely inside and outside of North America, has been enormously influential for research purposes, much of the world outside of North America also makes use of the mental disorders section (Chapter V) of the International Classification of Diseases, now in its 10th edition (ICD-10; World Health Organization, 1993). Hence, at least a brief summary of the ICD is in order.

The ICD-10 taxonomy of personality disorders overlaps with that of DSM-5, but it is considerably streamlined, consisting of 6 disorders rather than 10 . Specifically, the personality disorders in ICD-10 are paranoid personality disorder, schizoid personality disorder, dissocial personality disorder (which is similar to the classical construct of psychopathy; e.g., Cleckley, 1941, Hare, 1991/2003), anxious (avoidant) personality, dependent personality disorder, and anankastic personality disorder, the latter being essentially identical to DSM obsessivecompulsive personality disorder. ICD-10 also contains a "wastebasket" category allowing for diagnoses of individuals with other potentially impairing personality traits, such as those with pronounced narcissistic, passive-aggressive, and haltose features, the latter referring to such characteristics as self-centeredness, hedonism, and excitement-seeking. ICD-11 is still under discussion as of this writing, but one widely discussed - and radical - proposal for the personality disorders section is to eliminate all specific diagnoses and replace them with a single overarching category of personality disorder, separated by three gradations of severity (mild, moderate, severe; see Tyrer et al., 2015). Such a proposal is likely to engender scientific controversy, however, in view of research demonstrating striking differences in the personality trait correlates of many extant DSM and ICD conditions (see "Trait Models').

\section{The post DSM phase}

Our coverage of the post-DSM phase is of necessity brief, because we will cover new developments in the conceptualization and operationalization of personality disorders in forthcoming sections (see "Trait Models' and "Interpersonal Models"). Suffice it to say here that 
Personality Disorders: Scientific Status

the field of personality disorders has increasingly begun to move away from categorical models, which are not supported by the bulk of research evidence (Haslam et al., 2012), and toward alternative models, especially trait-based and prototype models. In this respect, we can regard DSM-5 Section III, although technically part of the DSM, as on the leading edge of this phase. Also of growing interest, again to be discussed later (see "Future Directions") are provisional approaches, such as the Research Domain Criteria (RDoC: Cuthbert \& Insel, 2013), which harness the power of indicators of well-validated brain-based systems, such as threat and approach systems, that are salient to both functional and dysfunctional personality adaptation.

Key Conceptual Quandaries

Although the study of personality disorders has witnessed substantial progress over the past several decades, it has consistently been hampered by deep-seated conceptual disagreements. Many of these fundamental differences strike to the heart of how to define personality disorders, as well as how to operationalize specific conditions within this category. We discuss four especially knotty conceptual issues here.

Five models of the relation between personality and psychopathology

One of the major impediments standing in the way of progress in personality disorder research has been the lack of a clear articulation of the nature of the intersection between these two traditionally disconnected domains. In a useful article, De Bolle, Beyers, De Clercq, and de Fruyt (2012) delineated five broad models of this fraught interrelationship (see also Widiger, 2011). To their list, we add one model of our own, and summarize this six models here, in a few cases modifying De Bolle et al.'s terminology slightly.

(1) The predisposition/vulnerability mode/ posits that personality traits boost the risk of developing a mental disorder. For example, neuroticism appears to increase the chances of developing later anxiety disorders and mood disorders, such as major depressive disorder (Watson \& Clark, 1984). 
Personality Disorders: Scientific Status

(2) The taxonicity model, which we append to De Bolle's et al.'s (2012) list, posits that personality and psychopathology differ qualitatively (in kind) rather than quantitatively (in degree), and thereby constitute two entirely different domains. A taxon, as noted by Meehl and Golden (1982), is a nonarbitrary class, or put somewhat differently, a discrete variable (category) that exists in nature, not merely in the minds of clinicians. A clear example of a taxon is the dominant gene disorder of Huntington's disease (Huntington's chorea); one either possesses the gene or one does not, and if a person carrying the gene lives long enough, he or she will develop the condition. For example, some authors have suggested that at least some DSM personality disorders, such as schizotypal personality disorder (Beauchaine, Lenzenweger, \& Waller, 2008), as well as some nonDSM personality disorders, such as psychopathic personality (Harris, Rice, \& Quinsey, 1994), differ qualitatively from normality. Scientific debate concerning the taxonic versus dimensional structure of schizotypy continues (Rawlings, Williams, Haslam, \& Claridge, 2008), although the lion's share of data suggests that psychopathic personality is dimensional rather than taxonic (Edens, Marcus, Lilienfeld, \& Poythress, 2006).

(3) The continuity mode/ posits that personality traits and psychopathology fall on the same dimension, but differ in severity. For example, from this perspective, avoidant personality disorder merely marks an extreme point on a spectrum of social anxiety. The continuity model is supported by research using taxometric procedures, which allow investigators to ascertain whether an observed distribution is underpinned by two or more discrete distributions. Such research is consistent with the possibility that, with the possible exception of schizotypal personality disorder and perhaps other Cluster A disorders, the DSM personality disorders merge imperceptibly into normality (Haslam et al., 2012).

(4) The complication/scar mode/ posits that psychopathology results in lasting changes in personality. In this respect, the temporal association between personality and psychopathology is reversed from that of the predisposition/vulnerability model. For 
Personality Disorders: Scientific Status

example, depression may contribute to enduring changes in certain personality traits, such as introversion, although the evidence for this hypothesis is mixed (Klein, Kotov, \& Bufferd, 2011; Rohde, Lewinsohn, \& Seeley, 1990).

(5) The pathoplasty model posits that personality and psychopathology are separable, but that personality often shapes the manifestation of psychopathology. For example, some authors have proposed that high levels of boldness, conscientiousness, or impulse control may channel psychopathic personality traits away from largely unsuccessful avenues, such as antisocial and criminal behavior, and toward largely successful avenues, such as business and politics (Lilienfeld, Watts, \& Smith, 2015), although this conjecture is controversial (Lynam \& Miller, 2012).

(6) Finally, the shared diathesis model proposes that personality disorders and other mental disorders stem from shared underlying predispositions (Krueger \& Tackett, 1998). For example, both borderline personality disorder and major depression, which covary substantially (Zimmerman \& Mattia, 1999a), may stem in part from individual differences in negative emotionality, namely, an enduring predisposition to experience aversive affects, such as anxiety, shame, hostility, and alienation, of all kinds (Watson \& Clark, 1984).

With the exception of Models 2 (taxonicity) and 3 (continuity), the aforementioned models are not mutually exclusive, underscoring the potential complexity of the relation between personality and psychopathology. For example, it is conceivable that certain personality traits, such as negative emotionality, (a) increase the risk of certain mental disorders (Model 1, the predisposition/vulnerability model), (b) in part persist as enduring residues of certain preexisting mental disorders (Model 3, the complication/scar model), (c) shape the overt expression of certain mental disorders (Model 5, the pathoplasty model), and (d) boost the risk of both personality disorders and other mental disorders.

Ego syntonicity versus ego dystoniicity 
Personality Disorders: Scientific Status

Another key point of contention is the extent to which individuals with personality disorders possess insight into the nature and extent of their psychopathology. Borrowing terminology from psychodynamic theorizing, descriptive psychiatry has commonly distinguished ego-dystonic from ego-syntonic conditions (Bronisch \& Monbour, 1988). Individuals with traditionally ego-dystonic (sometimes termed ego-alien) conditions, such as major depressive disorder or panic disorder, perceive their pathology as inconsistent with their self-concept ("this is not who I am"). In contrast, individuals with traditionally ego-syntonic conditions, such as psychopathic personality or the manic phase of bipolar disorder, perceive their "pathology" as consistent with their self-concept ("this is who I am"). Note that we placed the word "pathology" in the preceding sentence in quotation marks given that individuals with ego-syntonic conditions rarely, if ever, acknowledge that their signs and symptoms are pathological. Another relatively clear-cut instance of this distinction can be seen in the distinction between obsessivecompulsive disorder (OCD) and obsessive-compulsive personality disorder (OCPD), the latter to be discussed at greater length. Most, although not all (Matsunaga et al, 2002), cases of OCD are ego-dystonic, as individuals with this condition typically recognize that their symptoms (e.g., intense fears that they left a stove burner on) and signs (e.g., compulsive checking of the burner) are senseless; indeed, many patients are ashamed of, reluctant to admit to, them. In contrast, most or virtually all individuals with OCPD regard their personality features, such as extreme perfectionism, miserliness in spending, and an unwillingness to delegate tasks to others, as rational, if not eminently sensible (Bartz, Kaplan, \& Hollander, 2007).

Although some authors have argued that most or all personality disorders are egosyntonic (e.g., Hirschfeld, 1993), it is not at all evident that this is the case. For example, clinical lore implies that many and perhaps most individuals with avoidant personality disorder are motivated to change their behavior (Kantor, 2010), although there are few systematic data on this issue. The extent to which ego-dystonicity versus ego-syntonicity shapes the manifestation and prognosis of personality disorders remains largely unknown, largely owing to the absence 
Personality Disorders: Scientific Status

of construct-valid measures of this crucial distinction in the domain of personality and personality disorders. Measures of lack of insight into one's psychopathology, often termed anosognosia, have been developed for psychotic conditions (Amador \& Gorman, 1999), and a pressing need exists for their development for personality disorders.

More broadly, the extent to which individuals with personality disorders possess insight into their conditions remains a matter of dispute. For example, dating back at least to the classic writings of Cleckley (1941), many authors have contended that individuals with psychopathic personality (psychopathy) perceive little or nothing wrong with themselves and lack an adequate appreciation of the impact of their actions on others. Similarly, many clinical observers have regarded most individuals with narcissistic personality disorder, especially those with marked traits of "grandiose" (flamboyant, boastful) narcissism, as largely oblivious to their pathology (Dickinson \& Pincus, 2003).

Nevertheless, some recent research calls these longstanding assumptions into question. For example, in a community sample of participants recruited for being at high risk for psychopathy by virtue of their responding to an advertisement calling for participants who are charming, carefree, aggressive, and irresponsible but good at looking out for their interests, Miller, Jones, and Lynam (2011) found that scores on three well-validated self-report measures of psychopathy converged highly (median $r=64$ ) with observer reports of psychopathy, suggesting that individuals with marked psychopathic traits can often report veridically on their personality attributes. In an even more striking demonstration, Konrath, Meier, and Bushman (2014) found that across 11 studies, a one-item narcissism scale ("To what extent do you agree with this statement: I am a narcissist," rated on a 1-11 scale) correlated significantly and often moderately with a broad array of other indicators, including laboratory measures of aggression in response to ego threat and a host of well-validated questionnaire measures of narcissism. So perhaps many narcissistic people recognize their own narcissism after all (Carlson, 2013). More generally, data consistently demonstrate that self-reports of personality disorder pathology 
Personality Disorders: Scientific Status

tend to converge at least moderately with informant reports of such pathology, especially for the traits of Cluster B disorders (Klonsky \& Oltmanns, 2002). Collectively, these findings strongly suggest that the extreme position that self-reports are largely useless for individuals with personality disorder pathology (e.g., see Kagan, 2012) is empirically unjustified.

At the same time, the interpretation of these intriguing findings warrants clarification. In principle, highly psychopathic and highly narcissistic individuals may be able to accurately describe their emotions, thoughts, and behaviors without appreciating their pathology or grasping the gravity or impact of their actions on others. For example, a clinically paranoid individual can respond "True" to such items "I believe that others are out to get me" and "I'm sure that I'm being followed" without being aware that his or her beliefs are delusional. If this same principle applies to ego-syntonic personality disorders, valid self-reports of personality disorder pathology can co-exist in the absence of insight. This hypothesis awaits systematic investigation.

These ambiguities notwithstanding, there is little controversy that self-reports of personality pathology have their methodological limitations, especially their susceptibility to response styles (e.g., social desirability, acquiescence) and potential reliance on insight (Lilienfeld \& Fowler, 2006). In particular, informant reports may be helpful in detecting the "blind spots" of such pathology (Grove \& Tellegen, 1996; Oltmanns \& Turkheimer, 2009), especially for participants with largely ego-syntonic traits. Dovetailing with this possibility, Fiedler, Oltmanns, and Turkheimer (2004) reported that, in a sample of military recruits undergoing basic training, peer-reported personality disorder features consistently outperformed selfreported personality disorder features in predicting risk for premature discharge across a fouryear period. This trend held for the traits of all conditions save for obsessive-compulsive personality disorder and was especially marked for antisocial and borderline personality disorders. The intriguing exception for obsessive-compulsive personality disorder may reflect the fact that at least some features of this condition, such as perfectionism and diligence, may 
Personality Disorders: Scientific Status

be associated with relatively little impairment in everyday functioning (Skodol et al., 2002), or more speculatively, even enhanced functioning in certain settings (e.g., graduate school). Basic tendencies versus characteristic adaptations

Another important conceptual distinction in the personality disorders literature that warrants further consideration is that between basic tendencies and characteristic adaptations (McCrae \& Costa, 1995; see also Harkness \& Lilienfeld, 1997). Broadly speaking, basic tendencies are the core personality traits underpinning behavior, whereas characteristic adaptations are the behavioral manifestations of these traits. Pivotal to this distinction is the notion that similar if not identical basic tendencies can give rise to a plethora of different characteristic adaptations as a function of various moderators, such as cognitive variables, interests, life circumstances, and other personality traits, a notion similar to that of multifinality in developmental psychology (Lilienfeld, 2014). For example, prisoners and firefighters tend to exhibit similarly elevated scores on sensation seeking (Zuckerman, 1995), a trait capturing a disposition to pursue and experience novel stimuli. Perhaps high sensation seekers' inclination to seek out excitement and adventure can be differentially channeled into alternative outlets, one largely adaptive and the other largely maladaptive, as a function of still undetermined variables (see also Dickman's, 1990, distinction between functional and dysfunctional impulsivity). .

The distinction between basic tendencies and characteristic adaptations bears often unappreciated implications for the longitudinal stability of personality disorders, in part because many personality disorder criterion sets appear to be complex admixtures of basic tendencies and characteristic adaptations. For example, the diagnostic criteria for DSM-5 antisocial personality disorder (American Psychiatric Association, 2013) comprise such features as impulsivity and guiltlessness (which appear to be basic tendencies) as well as initiating physical fights and cruelty to animals (which appear to be characteristic adaptations). The former features may tend to be more stable than the latter. Indeed, in a review of the literature on the 
Personality Disorders: Scientific Status stability of personality disorder features, Clark (2009) found that the borderline personality disorder (BPD) criterion of emotional instability and anger proneness tends to be more consistent over lengthy stretches of time than does the BPD criterion of self-harm. The former criterion may be more likely to detect a longstanding affective disposition, whereas the latter may be more likely to detect a short-lived manifestation of this disposition (i.e., a characteristic adaptation) that is triggered by adverse life events.

The basic tendencies-characteristic adaptations distinction may also be relevant to the treatment of personality disorders. For example, many authors have concluded that psychopathy is essentially untreatable (see Salekin, 2002, for a demurral). Yet, in drawing this inference, they may have neglected to differentiate the core personality traits of psychopathy, such as lack of guilt and callousness, from their potential behavioral manifestations, such as rule-breaking and law-breaking. Although it may indeed be difficult or even impossible to alter psychopathic individuals' lack of remorse and empathy, at least given our current arsenal of psychotherapeutic and psychopharmacological techniques, the quest to modify their maladaptive behavioral expressions of the traits may be less quixotic (see Skeem, Polaschek, Patrick, \& Lilienfeld, 2011). This may be especially the case when intervention is initiated early in life, as meta-analyses typically suggest that treatments for childhood psychopathology are more effective when begun earlier than later in childhood (Weisz, Weiss, Alicke, \& Klotz, 1987).

\section{Lingering Conundrums and Controversies}

As noted earlier, the DSM personality disorders section has consistently been among the most, if not the most, frequently criticized portion of the manual (e.g., Clark, Livesley, \& Morey, 1997; Klonsky, 2000; Widiger, 1993), and for good reason. Growing research suggests that the 10 personality disorders in the DSM, although predictively useful in some cases (see “The DSM Personality Disorders: A Capsule Summary"), do not map on well to the state of 
Personality Disorders: Scientific Status

nature. Here, we review five longstanding problems and unresolved issues that have bedeviled the DSM personality disorders section virtually since its inception (see also Clark, 2007). Fortunately, a better appreciation of these challenges may ultimately point the way to their resolution.

\section{The dilemma of inter-rater reliability}

The personality disorders section of the DSM has consistently been among the least reliable sections of the manual, at least with respect to inter-rater reliability (Zanarini et al., 2000). Such reliability problems are not entirely unexpected given that, with the partial exception of antisocial personality disorder (see "The DSM Personality Disorders: A Capsule Summary"), the DSM personality disorders consist primarily of criteria requiring a considerable amount of diagnostic inference. Compare, for instance, the criterion "recurrent episodes of binge eating" (American Psychiatric Association, 2013, p. 245), which is the first DSM-5 criterion for bulimia nervosa, with the criterion "has a grandiose sense of self-importance" (American Psychiatric Association, 2013, p. 669), which is the first DSM-5 criterion for narcissistic personality disorder. It is evident that the latter criterion, in contrast to the former, refers to subjective self-appraisals that may be challenging for diagnosticians to ascertain accurately.

At the same time, the creation of structured psychiatric interviews has clearly helped in this regard, and data suggest that the interrater reliabilities of personality disorder diagnoses derived from such interviews tend to exceed those derived from unstructured interviews (Zimmerman, 1994). In a study of psychiatric outpatients using the DIPD, Zanarini et al. (2000) reported moderate to high inter-rater reliabilities (kappa=.40 to .75 ) for DSM-IV personality disorder diagnoses save for antisocial personality disorder, whose kappa was 1.0, probably reflecting the this diagnosis' reliance on explicit behavioral criteria, such as arrests (Lilienfeld, 1994). Most studies have similarly reported moderate to high inter-rater reliabilities for most DSM personality disorder diagnoses (e.g., First, 1995; Lobbestael, Leurgans, \& Arntz, 2011). In broad brush, these results suggest that the DSM personality disorders display reasonable levels 
Personality Disorders: Scientific Status

of inter-rater reliability when assessed using structured interviews, although there is room for improvement.

Still, these moderate to high inter-rater reliabilities conceal a deeper difficulty that has received insufficient attention. Although inter-rater reliabilities are generally adequate when using the same interview, diagnostic concordance plummets, often substantially, when raters use different instruments. For example, diagnostic agreement tends to be poor or at best moderate when different structured interviews are used, and often poor when structured interviews are compared with self-report measures (Perry, 1992; see also Smith, Klein, \& Benjamin, 2003). In general, self-report measures tend to yield considerably higher prevalences of personality disorders than do interview-based measures, probably in part because the former do not allow for interviewer probing and follow-ups (Oldham \& Rosnick, 1990). Some of the discrepancy between interview and self-report measures also reflects the substantial loss in psychometric information incurred by dichotomizing continuous scores into categories; the correlations between dimensionally-assessed interview and self-report measures of personality disorders tend to be considerably higher than those between categorically-assessed interview and self-report measures (Smith et al., 2003; Zimmerman \& Coryell, 1990).

\section{"Comorbidity"}

An ideal taxonomy yields categories that are largely mutually exclusive, with few or no intermediate cases (Frances, 1980). Yet across its many editions, the DSM personality disorders section has been plagued by a vexing problem known, somewhat misleadingly, as comorbidity. Medical epidemiological Alvan Feinstein (1970) coined the term comorbidity to refer to the co-occurrence of a "distinct clinical entity that has existed or that may occur during the clinical course of a patient who has the index disease under study" (pp. 456-457). Some scholars have voiced concerns about the application of the "comorbidity" concept to descriptive psychopathology given that it is unclear how many DSM conditions are distinct clinical entities (Lilienfeld, Waldman, \& Israel, 1994; but see Widiger \& Ford-Black, 1994 for a dissenting view 
Personality Disorders: Scientific Status

on this application of this concept). Such terminological disagreements aside, extremely high levels of covariation among putatively different conditions may raise questions concerning their independence as constructs. In the psychometric literature, the counterpart of comorbidity is discriminant validity (Campbell \& Fiske, 1959), a term referring to the extent to which measures of a construct are largely uncorrelated with measures of constructs with which they are theoretically separable.

The extent of the comorbidity problem is difficult to overstate. In one study of over 1000 patients (Stuart et al., 1998), individuals with one DSM personality disorder met criteria for an additional 1.7 DSM-III-R personality disorders on average; $9.4 \%$ met criteria for 4 or more personality disorders. Only $18 \%$ of patients with a personality disorder did not meet criteria for at least one other personality disorder, indicating that comorbidity is much more often the rule than the exception. In one especially extreme case, one research participant simultaneously met criteria for all 10 DSM-IV (and DSM-5) personality disorders (Widiger et al., 1998; see also Lilienfeld, Smith, \& Watts, 2016)! One can only assume that this individual must have been a handful. Although the degree of comorbidity is especially marked within each of three DSM clusters, it is pronounced even across clusters. For example, in a large epidemiological survey of the U.S. population, Tomko, Trull, Wood, and Sher (2014) reported that individuals with borderline personality disorder - a Cluster B disorder - were 20.8 times more likely than were other individuals to meet criteria for Cluster A personality disorders and 9.5 times more likely to meet criteria for Cluster $\mathrm{C}$ personality disorders.

The magnitude of personality disorder co-occurrence tends to be considerably higher in clinical than in community samples (Oltmanns, Rodrigues, Weinstein, \& Gleason, 2014), almost certainly owing at least in part to a well-known epidemiological artifact known as Berksonian bias (Berkson, 1946) as well as to a less familiar but equally important artifact known as clinical selection bias (du Fort, Newman, \& Bland, 1993). Berksonian bias results from the fact that a person with two conditions can obtain treatment for either one, whereas clinical selection bias 
Personality Disorders: Scientific Status

results from the fact that a person with one condition is more likely to seek treatment when he or she has a second condition. For example, individuals with narcissistic personality disorder are unlikely to seek treatment, but they might be substantially more inclined to do if they also meet criteria for obsessive-compulsive personality disorder, as the latter condition may engender greater work-related or interpersonal impairment.

Nevertheless, the comorbidity problem is commonly overlooked in everyday clinical practice due to a phenomenon known as diagnostic overshadowing (Garb, 1998), whereby a highly dramatic condition, such as borderline personality disorder, leads practitioners to overlook less salient co-occurring conditions, such as dependent personality disorder. Data suggest that when structured interviews are used, the magnitude of comorbidity is much higher than when unstructured interviews are used (e.g., Zimmerman \& Mattia, 1999b), almost certainly because the former interviews force diagnosticians to attend to all DSM criteria.

Rampant comorbidity is a red flag that the DSM personality disorder system is not drawing the correct diagnostic boundaries, assuming that such boundaries should be drawn in the first place. Other authors (e.g., Maj, 2005) have gone further, arguing that such comorbidity reflects the propensity of the DSM to attach different names to slightly different manifestations (formes frustes) of a shared predisposition, a logical error known as the jangle fallacy (Block, 1995). Given that most personality disorders appear to be complex constellations or configurations of normal-range personality dimensions (e.g., antagonism, low conscientiousness, introversion; see Widiger \& Trull, 2007), it is only to be expected that many of these conditions would display substantial covariation. After all, these disorders reflect highly overlapping densifications of dimensions in multivariate space.

As an analogy, imagine that one were studying professional singers, and that one rated their singing ability along five dimensions: Singing country music, Singing rock music, Singing opera, Singing folk music, and Singing nightclub music. Imagine further that the scores on these five dimensions were correlated an average of $r=.60$, probably not terribly different from the 
Personality Disorders: Scientific Status

mean correlations of dimensional scores across many personality disorder dimensions. Then, imagine that one drew arbitrary cut-offs on each of the five dimensions, classifying each person as "Excellent singer" or not on each dimension. One would almost surely find high levels of "comorbidity" (co-occurrence) among these categories, so that the category of Excellent rock singer, for instance, were highly "comorbid" with that of Excellent folk singer. Referring to such co-occurrence as "comorbidity" would almost certainly be misleading, however, as the substantial overlap probably reflects the fact that one is arbitrarily carving out one overarching dimension of singing ability into narrower subdimensions, and in turn creating arbitrary categories within each subdimension. Similarly, the high "comorbidity" among histrionic, borderline, and narcissistic personality disorders, for instance, may merely reflect the fact that these three conditions are expressions of one or, more likely, several. shared underlying personality dimensions, such as negative emotionality and antagonism (low agreeableness). Large number of unclassified cases

As noted earlier, an optimal classification system consists of categories that yield few intermediate cases (Frances, 1980). Yet in many studies of personality disorders, especially in clinical samples (OtImanns et al., 2014), one of the most frequent diagnoses - if not the most frequent diagnosis - is NOS (Not Otherwise Specified), meaning that most patients with mental disorders do not fit into any extant category (Verheul \& Widiger, 2004; Westen, 2012). Such patients must be diagnosed by means of a "wastebasket category" that encompasses individuals who are undeniably personality disordered but whose signs and symptoms do not meet criteria for any extant personality disorder diagnosis.

The "NOS problem" offers yet another indication that the DSM personality disorders taxonomy is not "carving nature at its joints." Some of the NOS problem stems from the DSM's "overspecification" of diagnostic criteria (Hyman, 2010, p. 166): In its laudable efforts to provide standardized diagnostic criteria and algorithms, the DSM inadvertently excludes many patients who suffer from the conditions in question but who fall barely short of its largely arbitrary 
Personality Disorders: Scientific Status

diagnostic thresholds. Furthermore, the NOS problem very likely reflects the fact that the DSM is imposing largely arbitrary categories on a series of correlated dimensions. Hence, it is not surprising that some of these categories "miss" individuals with significant personality pathology. Phenotypic heterogeneity

One consequence of the polythetic system of recent DSM personality disorder criterion sets, in which diagnostic criteria are neither singly necessary nor jointly sufficient for their respective diagnoses, is phenotypic heterogeneity: Individuals meeting criteria for the same diagnosis may exhibit extremely different patterns of signs and symptoms. For example, there are 256 different ways of meeting DSM-5 criteria for borderline personality disorder (Lilienfeld et al., 2016; Zimmerman, 2011). Even more strikingly, two individuals can meet criteria for obsessive-compulsive personality disorder without sharing a single criterion (Widiger, 2007)!

Although phenotypic heterogeneity does not necessarily imply heterogeneity at the level of etiology, it is implausible that constellations of differing signs and symptoms that are themselves often only weakly or modestly correlated would stem from identical causal factors. Hence, phenotypic heterogeneity is likely to impede efforts to identify commonalities among individuals satisfying the same personality disorder diagnosis, as well as efforts to ascertain the pathophysiology of personality disorders.

Longitudinal instability

A core assumption underpinning the concept of personality disorders, as well as the demarcation between Axis I and Axis II in DSM-III, DSM-III-R, and DSM-IV (American Psychiatric Association, 1980, 1987, 2000) is that personality disorders are temporally stable, reflecting lasting predispositions to psychopathology. For example, Zimmerman (1994) wrote that "In contrast to Axis I disorders, PDs represent stable, long-term, maladaptive characteristics based on how individuals act in different situations, on how they perceive and interact with the environment, and on the reasonableness of their behaviors and attitudes" (p. 238). 
Personality Disorders: Scientific Status

Nevertheless, growing research raises questions concerning the degree of this longitudinal stability (Clark, 2005b). In retrospect, the finding that personality disorder features often change over lengthy stretches of time - fortunately most often in the direction of clinical improvement -should not have been unexpected given the burgeoning literature on the longterm malleability of normal-range personality traits. For example, meta-analyses point to moderate mean-level changes in several personality traits across lengthy stretches of time, with increases in conscientiousness and emotional stability (reversed neuroticism) and some features of extraversion (especially those tied to interpersonal dominance) between ages 20 and 40, and increases in agreeableness and decreases in openness in middle to old age (Roberts, Walton, \& Viechtbauer, 2006). In contrast, the rank-order stability of personality traits starting the mid-20s tends to be considerably higher, reflecting the fact that although people's personality traits are changing in adulthood, their standing relative to each other on such traits remains reasonably consistent (Roberts \& DelVecchio, 2000).

Coinciding with these well-established findings, as well with findings that most or all DSM personality disorders appear in part to reflect combinations or configurations of normalrange personality traits, changes in personality disorder diagnoses and features are apparent in many patients over time as well (Clark, 2009; Lenzenweger, 1999; Widiger, 2011). For example, the Collaborative Longitudinal Study of Personality Disorders (CLPS) revealed substantial decreases in personality disorder features across 6-month, 1 year, and 2 year follow-up intervals among some patients diagnosed with a personality disorder at the outset of the study. After 2 years, a full third (32\%) of patients met 2 or fewer DSM criteria from their principal personality disorder diagnosis (Grilo et al., 2004). Even among patients with borderline personality disorder, a condition traditionally regarded as quite stable over time (Pope, Jonas, Hudson, Cohen, \& Gunderson, 1983), 14\% (23 of 160) met 2 or fewer criteria for this condition 6 months later (Gunderson et al., 2003). Perhaps not surprisingly, however, stability over time tends to be higher when personality disorder features are measured dimensionally rather than 
Personality Disorders: Scientific Status

categorically (Clark, 2007), as dimensional measures reduce error by preserving more finegrained differentiations of individual differences.

In aggregate, these and other findings (see Clark, 2007, for a review) suggest that although there is clearly longitudinal stability in personality disorder traits, especially when measured continuously, there are substantial changes, and generally improvements, over time in sizeable subsets of individuals. These results call for a reconsideration of the longstanding assumption that personality disorders are necessarily highly consistent over lengthy time periods (e.g., Zimmerman, 1994).

\section{Models of Personality Disorders}

Many of the findings we have reviewed point to a pressing need to reevaluate the categorical model of personality disorders instantiated in DSM-5 and ICD-10. As we have seen, evidence suggests that with the possible exception of schizotypal personality disorder and perhaps other Cluster A conditions, personality disorders differ from normality in degree than in kind (Haslam et al., 2012; Lenzenweger, McLachlan, \& Rubin, 2007), suggesting that dimensional models afford a better fit to the state of nature than do categorical models for most personality disorders.

Even putting aside such evidence, there is ample reason to favor dimensional models on measurement grounds alone, as continuous measures of psychopathology almost always provide higher levels of reliability and convergent validity than do categorical measures (Markon, Chmielewski, \& Miller, 2011). This principle holds true, incidentally, even when measuring conditions that are taxonic in nature, because dimensional indices reduce measurement error surrounding the cut-off between taxon and complement (non-taxon) classes (Snyder \& Gangestad, 1986).

As noted earlier, dimensional models of personality traits address the comorbidity problem given that most personality disorders appear to be configurations of continuously distributed traits in multivariate space. Dimensional models further also allow us to sidestep the 
Personality Disorders: Scientific Status

problem of arbitrary diagnostic thresholds that have long bedeviled most or all DSM categories, including the personality disorders (Widiger, 2009). . Because there is no clear dividing line or "point of rarity" demarcating normal from abnormal personality, the DSM personality thresholds are in most or all cases scientifically arbitrary. To take just one example, although DSM-5 requires individuals to meet 4 or more of 7 criteria for the diagnosis of avoidant personality disorder (American Psychiatric Association, 2013, pp. 672-673), there is no reason to believe that this cut-off point corresponds to a genuine breaking point in nature. For instance, there is no scientific evidence that individuals who meet only 3 of the 7 criteria for this condition are markedly distinct from those who meet 4 or more criteria, as implied by a categorical model. Nor is there evidence that individuals who meet 4 of the criteria are more similar to those who meet all 7 criteria than do those who meet only 3 criteria, again as implied by a categorical model.

Here, we examine two alternative dimensional conceptualizations of personality disorders that are conceptually and empirically promising, and that have received growing attention over the past two decades: trait models and interpersonal models (see also Widiger \& Frances, 1985; Widiger \& Simonsen, 2005). As we will discuss later (see "Future Directions"), these two sets of models may not be mutually exclusive and may benefit from at least partial synthesis.

\section{Trait models}

Over the past several decades, the five-factor model (FFM) has become the most widely accepted framework for the structure of personality (but see Block, 1995, and Tellegen, 1993, for thoughtful alternative positions). The FFM conceptualizes personality as underpinned by five broad dimensions: extraversion, neuroticism, agreeableness, conscientiousness, and openness to experience (McCrae \& Costa, 1987). In most FFM models, these overarching dimensions are in turn conceptualized as underpinned by multiple lower-order facets; for example, in the widely used Revised Neuroticism Extraversion Openness Personality Inventory (NEO-PI-R), the 
Personality Disorders: Scientific Status

higher-order domain of neuroticism is subdivided into the facets of anxiety, hostility, depression, self-consciousness, impulsiveness, and vulnerability to stress (Costa \& McCrae, 1992).

Although initially conceptualized as a model of normal personality, growing evidence suggests that the FFM accounts for variations in abnormal personality as well (Widiger \& Trull, 2007), although with potential problems of restriction of range with regard to the more maladaptive levels of FFM traits.

Research on the relation of the FFM and DSM personality disorders has been extensively reviewed elsewhere (Widiger \& Costa, 2013) and will be only briefly summarized here. In broad brush, the FFM dimensions of neuroticism and antagonism (reversed agreeableness) are the most consistent correlates of dimensionally assessed DSM personality disorders (Saulsman \& Page, 2004). For example, neuroticism tends to be an especially marked correlate of paranoid, schizotypal, borderline, avoidant, and dependent personality disorders, and antagonism tends to be an especially marked correlate of paranoid, schizotypal, antisocial, borderline, and narcissistic personality disorders. Nevertheless, extraversion and conscientiousness also help to differentiate certain personality disorders; for example, extraversion tends to be elevated in histrionic personality disorder yet low in avoidant personality disorder; conscientiousness tends to be elevated in obsessive-compulsive personality disorder yet low in antisocial personality disorder. Traditional measures of openness to experience, in contrast, tend to be largely unrelated to DSM personality pathology, perhaps because they are largely independent of psychoticism, a key feature of Cluster A personality disorders (Chmielewski, Bagby, Markon, Ring, \& Ryder, 2014). The findings just reviewed focus on the domain level of the FFM; once we move to the facet level, the findings become still more complex and differentiated (Samuel \& Widiger, 2008). For example, although antisocial personality disorder features tend to be modestly and positively associated with neuroticism, this relation holds true only for certain facets, such as angry hostility and impulsiveness, but not 
Personality Disorders: Scientific Status

for anxiety or self-conscientiousness, both of which are negligibly associated with antisocial personality disorder features.

A competing model that also has attracted its fair share of adherents is the three factor model (Tellegen \& Waller, 2008). This model instead conceptualizes personality as comprising three broad higher-order dimensions, often called positive emotionality (which is similar to but broader than extraversion), negative emotionality (which is similar to but broader than neuroticism), and constraint versus disinhibition (which is similar to but broader than conscientiousness). Each of these higher-order factors in turn subsumes several lower-order factors, which are measured by subscales. Data suggest that the FFM and three factor models map onto much of the same factor analytic territory, but at different levels of granularity (Church, 1994; Markon, Watson, \& Krueger, 2005). In particular, positive emotionality largely subsumes extraversion and some features of openness, negative emotionality largely subsumes neuroticism and antagonism, and constraint versus disinhibition largely subsumes conscientiousness and some features of (reversed) openness.

Although data suggest that the FFM may be superior to the three factor model in statistically predicting features of many or most DSM personality disorders (e.g., Gaughan, Miller, Pryor,\& Lynam, 2009)thesefindings probably reflect the greater granularity of the NEOPI-R. Indeed, although some might be tempted to conclude from such findings that the FFM is superior to the three factor model, this inference would be unjustified. Most philosophers of science agree that prediction is not equivalent to explanation (Shmueli, 2010). More broadly, it is likely that these two competing personality models help to account for personality pathology but at differing levels of specificity, each of which affords distinctive information. Imagine two reflecting telescopes whose lenses differ vastly in size; the telescope with the larger lens will have much higher resolution, allowing astronomers to perceive extremely distant galaxies in greater detail. Yet if the astronomer using the much more powerful telescope trains her focus solely on minor details within distant galaxies, she may miss what the astronomer with the 
Personality Disorders: Scientific Status

smaller lens telescope will detect, namely, that these galaxies coalesce into much larger galactic clusters. More broadly, one might reasonably contend that the goal of personality disorders science should not be to account for variance in the extant DSM personality disorders, which are surely do not map on cleanly to the state of nature, but rather to better map out and understand the broader domain of abnormal personality.

Although trait models hold considerable promise, they leave certain questions unanswered. In particular, such models leave substantial amounts of variance in personality disorder trait measures unaccounted for, even when the facet level is examined (Samuel \& Widiger, 2008). These findings harken back to the distinction between basic tendencies and characteristic adaptations (Harkness \& Lilienfeld, 1997). Specifically, they raise the intriguing possibility that two individuals with similar or identical patterns of personality traits may not necessarily display the same pattern of overt personality pathology, perhaps because the manifestations of these traits are moderated by non-personality variables, such as cognitive dispositions, interests, and life experiences. If so, these results may indicate that personality traits are necessary but not sufficient for a full understanding of personality disorders.

In addition, investigations and meta-analyses of such investigations consistently suggest that certain personality disorders, such as obsessive-compulsive and schizoid personality disorders, are not well accounted statistically by the FFM (Saulsman \& Page, 2004). For example, FFM measures probably do not account for more than two-thirds of the variance in the dimensionally-assessed features of personality disorder (Trobst, Ayearst, \& Salekin, 2013). The meaning of this finding requires clarification. In part, it is likely to reflect the fact that FFM does not adequately capture maladaptive variants of certain personality dimensions; for example, it may not provide sufficient coverage of pathological conscientiousness (viz., perfectionism; see Hewitt \& Flett, 2007) to afford adequate statistical prediction of obsessive-compulsive personality disorder traits. Nevertheless, for certain conditions, especially Cluster A personality disorders, cognitive dimensions that lie partially outside the traditional personality domain, such 
as cognitive slippage (Meehl, 1962), may be needed to account for the full range of pathological variation.

Interpersonal models

Going back at least to the classic writings of psychiatrist Harry Stack Sullivan (1955), psychologists have long recognized that many forms of personality pathology are inherently interpersonal. The construct of narcissistic personality disorder would appear to hold little meaning unless other people were around to admire narcissistic individuals, and the construct of dependent personality disorder would appear to hold little meaning unless others were around for dependent individuals to depend on. In contrast, a person will schizophrenia would very likely demonstrate pronounced reality impairments even if stranded on a deserted island. Moreover, data demonstrate that maladaptive traits linked to personality disorders are associated with marked psychosocial, and often interpersonal, dysfunction. For example, among psychiatric outpatients, disinhibition, a personality trait linked to elevated risk for several personality disorders, including borderline and antisocial personality disorders, is associated with heightened levels of social dysfunction (Ro \& Clark, 2012).

Factor analyses have long suggested that interpersonal behavior can be described by individual differences in two broad and essentially orthogonal (uncorrelated) dimensions of social functioning. These dimensions have gone by different names and have been conceptualized in slightly different ways (Kiesler, 1983; Leary, 1957; Wiggins, 1979), but have commonly been labeled dominance (or power) and affiliation (or warmth; see Widiger \& Frances, 1983). Because specific trait terms, such as friendliness and mistrust, that capture these two broad dimensions tend to form a circle in factor-analytic space around these two axes, such models are commonly called circumplex models.

Data suggest that circumplex models are helpful for characterizing many DSM personality disorders, many of which appear to reflect differing configurations of extreme scores on these interpersonal dimensions (Hopwood, Wright, Ansell, \& Pincus, 2013; McLemore \& 
Personality Disorders: Scientific Status

Benjamin, 1979; Trobst et al., 2013). For example, antisocial and narcissistic personality disorder traits tend to fall in the quadrant characterized by high dominance and low affiliation; in contrast, dependent personality disorder traits tend to fall in the quadrant characterized by low dominance and high affiliation (Wiggins \& Pincus, 1989). At the same time, data suggest that the interpersonal circumplex is insufficient to account for the features of certain personality disorders, such as schizotypal and borderline personality disorders (Widiger \& Costa, 1994), raising the possibility that these conditions involve more than social dysfunction. For example, a comprehensive account of schizotypal personality disorder is likely to require cognitive dysfunction, and a comprehensive account of borderline personality disorder is likely to require dysfunction in affect regulation.

The DSM-5 Personality Disorders: A Thumbnail Sketch

With this conceptual background in mind, we can now briefly review the key descriptive features and correlates of each DSM-5 personality disorder. By definition, each condition emerges by early adulthood and is associated with distress, impairment, or both. Specifically, for each personality disorder, we succinctly summarize its clinical description and overlap with other conditions, its prevalence and demographic correlates, potential etiological correlates, and when controlled data are available, treatment.

\section{Cluster A: The Odd, Eccentric Cluster}

Paranoid personality disorder

Clinical description and overlap with other conditions

DSM-5 describes paranoid personality disorder as marked by "a pervasive distrust and suspiciousness of others such that their motives are interpreted as malevolent" (American Psychiatric Association, 2013, p. 649). Its key diagnostic criteria include suspicion of others without adequate foundation (e.g., believing that others are trying to steal his or her research 
Personality Disorders: Scientific Status

ideas); unjustified doubts about the trustworthiness or loyalty of others (including romantic partners and close friends); perceiving malicious intent in others' innocuous statements or actions; and an unwillingness to confide in others. As associated features, DSM-5 notes that such individuals are often perceived by others as cold and as devoid of tender emotions.

Because individuals with paranoid personality disorder commonly question others' motives, they are often needlessly combative in interpersonal situations. Commonly, they carry longstanding grudges and keep mental lists of their purported "enemies" (Bernstein \& Useda, 2007).The character Travis Bickel, portrayed by Robert DeNiro in the film Taxi Driver (1976), displays many of the hallmark features of this condition.

Perhaps not surprisingly, paranoid personality disorder is one of the personality disorders most strongly associated with reductions in overall quality of life (Triebwasser, Chemerinski, Roussos, \& Siever, 2013), almost surely in part because individuals with this condition frequently alienate friends and co-workers. In one study, paranoid personality traits were associated with heightened physical aggression and antisocial behavior in a nonclinical sample (Berman, Fallon \& Coccaro, 1998). Paranoid personality disorder covaries substantially with a number of other personality disorders, including schizotypal and borderline personality disorders (American Psychiatric Association, 2013).

Prevalence and demographic correlates

The prevalence 1 of paranoid personality disorder in the general population has been estimated to be approximately 2-4.5\% (American Psychiatric Association, 2013). Although data suggest higher rates of this condition among males than females in clinical samples (Bernstein \& Usada, 2007), there is no clear evidence of sex differences in the general population.

\section{Potential etiological correlates}

Little is known about the etiology of paranoid personality disorder, although some data point to a familial co-aggression of paranoid personality disorder with schizophrenia (Kendler et al., 1993). Perhaps more than those with any personality disorder, individuals with this 
Personality Disorders: Scientific Status condition report high rates of early abuse and neglect (Bierer et al., 2003). Nevertheless, it is unclear whether early abuse and neglect are causal, or whether reports of these experiences, which are at times ambiguous, reflect retrospective recall biases. For example, people with marked paranoid traits may be especially prone to recollecting emotionally distant parents as cruel, harsh, or neglectful. Longstanding data have also pointed to heightened levels of paranoid ideation among two groups of individuals: (a) those with hearing loss (Cooper, Kay, Curry, Garside, \& Roth, 1974; Triebwasser et al., 2013) and (b) recent immigrants to a country, especially one characterized by a different language and culture than those of the immigrant (Newhill, 1990). Nevertheless, the relevance of these findings to paranoid personality disorder per se is unclear.

\section{Treatment}

There are no controlled psychological or pharmacological intervention studies on paranoid personality disorder. Because paranoid personality disorder tends to be ego-syntonic,

${ }_{1}$ Although we adopt the term "prevalence" in this section of the chapter when describing the epidemiology of each DSM personality disorder, we again note that this term is technically inappropriate for most personality disorders given evidence that they are dimensional rather than taxonic in nature (Haslam et al., 2013).

individuals with this condition may not be highly motivated to seek out or follow through on treatment.

Schizoid personality disorder

Clinical description and overlap with other conditions

DSM-5 describes schizoid personality disorder as marked by "a pervasive pattern of detachment from social relationships and a restricted range of emotions in interpersonal settings" (American Psychiatric Association, 2013, p. 653). Its key diagnostic criteria include a 
decided preference for solitary activities; indifference to praise or criticism; a paucity of powerful outwardly expressed emotions; and lack of interest in long-term romantic relationships. As associated features, DSM-5 notes that individuals with this condition are frequently described as drifting aimlessly from one life pursuit to another, as having few or no close friends, as being loners, and as dating infrequently. In contrast to individuals with avoidant personality disorder, who typically yearn for social contact but are terrified of rejection, individuals with schizoid personality disorder typically have little interest in social contact (Millon, 1969). At the risk of oversimplification, they are alone but not lonely. The enigmatic character of Rupert Pupkin, portrayed by Robert DeNiro in the film The King of Comedy (1982), displays many of the hallmark features of this condition.

Data suggest that self-described "asexuals" are substantially overrepresented among individuals with this condition (Triebwasser, Chemerinski, Roussos, \& Siever, 2012) and that this condition is associated with perhaps the greatest interpersonal and achievement-related impairment of any DSM personality disorder (e.g., Cramer, Torgersen, \& Kringlen, 2006). There is substantial diagnostic overlap between schizoid personality disorder and what DSM-IV (American Psychiatric Association, 2000) called "Asperger's syndrome," which in DSM-5 would be classified as a high functioning form of autism spectrum disorder (Mittal, Kalus, Bernstein, \& Siever, 2007); nevertheless, it is unclear whether these two conditions share important etiological underpinnings.

\section{Prevalence and demographic correlates}

The prevalence of schizoid personality disorder in the general population has been estimated to be approximately 3-5\% (American Psychiatric Association, 2013). Individuals with this condition may be markedly underrepresented in clinical settings, largely because they experience relatively little distress and rarely perceive themselves as disordered. The disorder appears to be slightly more common in males than females (Mittal al., 2007).

Potential etiological correlates 
Personality Disorders: Scientific Status

Little is known about the etiology of schizoid personality disorder, although twin studies suggest that it is modestly heritable (in one study, 29\%; see Kendler et al., 2007). Data bearing on whether schizoid personality disorder belongs in the schizophrenia spectrum have been mixed. Some family studies point to significant co-aggregation of this condition with schizophrenia and schizotypal personality disorder, whereas others do not (Mittal et al., 2007).

Treatment

There are no controlled psychological or pharmacological intervention studies on schizoid personality disorder. Because, like paranoid personality disorder, schizoid personality disorder tends to be ego-syntonic, individuals with this condition may not be highly motivated to seek out or follow through on treatment.

Schizotypal personality disorder

\section{Clinical description and overlap with other conditions}

DSM-5 describes schizotypal personality disorder as characterized by "a pervasive pattern of social and interpersonal deficits marked by acute discomfort with, and reduced capacity for, close relationships as well as by cognitive or perceptual distortions and eccentricities of behavior" (American Psychiatric Association, 2013, p. 685). According to DSM5 , its key features include ideas of reference (holding beliefs that innocuous events, such as a commercial mentioning one's name, hold personal significance); magical thinking (holding beliefs that two logically unconnected events cause each other) and their unusual beliefs; strange perceptual experiences (e.g., perceiving that one's face is subtly changing shape while staring at it in mirror); excessive suspiciousness and social anxiety; and oddities in speech, dress, and physical appearance. DSM-5 also lists several features commonly associated with the condition, including brief psychotic experiences, typically in response to stressors, and depressive episodes.

Following from the writings of Rado (1956), Meehl (1962) posited that "schizotypy," a construct that bears marked similarities to the DSM operationalization of schizotypal personality 
Personality Disorders: Scientific Status

disorder, is a milder manifestation of the same diathesis that predisposes to schizophrenia; Meehl placed particular emphasis on the role of anhedonia (a pervasive loss of interest and pleasure) in this condition, an emphasis that is largely absent from the DSM. Consistent with Meehl's conjectures, individuals with schizotypal personality disorder at are substantially heightened risk for conversion to psychotic disorders, especially schizophrenia (Raine, 2006). Specifically, longitudinal studies suggest that between $20 \%$ and $40 \%$ of adolescents with schizotypal personality disorder go on to develop schizophrenia, a prevalence 20 to 40 times higher than the typical population base rate (approximately $1 \%$ ) of schizophrenia (Bollini \& Walker, 2007). Schizotypal personality disorder also overlaps moderately with schizoid personality disorder, but the former condition is marked not only by attenuated "negative" symptoms, such as withdrawal and lack of motivation, as in schizoid personality disorder, but also by attenuated "positive symptoms," such as peculiarities in thinking and behavior.

Prevalence and demographic correlates

DSM-5 estimates the prevalence of schizotypal personality disorder in the general population as ranging from approximately $.5 \%$ to as high as $4.5 \%$; Bollini and Walker (2007) contended that the most reasonable estimate is $3 \%$ given that it derived from a phone interview sample of the general population (Zimmerman \& Coryell, 1990). Although there are no marked sex differences in overall population prevalence, there are indications that men exhibit slightly higher rates than females (American Psychiatric Association, 2013). Moreover, women appear to be more likely than men to display the "positive symptoms" of the disorder, whereas men appear to be more likely than women to display the "negative symptoms" (Raine, 1992). Some authors have reported elevated rates of schizotypal personality disorder in Asian-Americans and AfricanAmericans (Chmielewski, Fernandes, Yee, \& Miller, 1995); assuming that this finding is replicable, it is unclear whether it reflects the influence of genetic factors, cultural factors, or both. 
Personality Disorders: Scientific Status

A large body of literature suggests that schizotypal personality disorder is not only moderately heritable (Farmer, McGuffin, \& Gottesman, 1987), but also genetically associated with schizophrenia. For example, adoption data demonstrate that schizotypal personality disorder is overrepresented in the first-degree biological relatives, but not first-degree adoptive relatives, of probands with schizophrenia (Kendler \& Gruenberg, 1984).

Corroborating its genetic ties to schizophrenia, schizotypal personality disorder is characterized by many of the same cognitive, neurological, and functional and structural brain abnormalities as observed in schizophrenia (Bollini \& Walker, 200\7). For example, like individuals with schizophrenia, individuals with schizotypal personality disorder tend to display deficits in working memory and executive functioning, high rates of smooth pursuit eye movement dysfunction, and diminished frontal lobe gray matter volume. Nevertheless, these and other findings tend to be less pronounced in schizotypal personality disorder than in schizophrenia (Chemerinski, Triebwasser, Roussos, \& Siever, 2013), consistent with the contention that the former is a somewhat milder form of the latter.

\section{Treatment}

Although research suggests that cognitive-behavioral therapy may be slightly helpful in ameliorating some of the symptoms of schizophrenia (Jauhar, McKenna, Radua, Fung, Salvador, \& Laws, 2014), there are no controlled studies of this or any other psychotherapeutic modality for individuals with schizotypal personality disorder. A small body of randomized placebo-controlled trials points to the potential efficacy of atypical antipsychotics, such as Risperidone (Risperdal), for the positive and negative features of schizotypal personality disorder (Koenigsberg et al., 2003).

Cluster B: The dramatic, emotional cluster

Antisocial personality disorder

Clinical description and overlap with other conditions 
Personality Disorders: Scientific Status

DSM-5 describes antisocial personality disorder as marked by "a pervasive pattern of disregard for and violation of the rights of others since age 15" (American Psychiatric Association, 2013, p. 659). Antisocial personality disorder is unique among DSM personality disorders in that its diagnosis is explicitly historical. Inspired by the classic longitudinal work of sociologist Lee Robins (1966), who identified childhood and adolescent predictors of adult antisocial behavior among individuals referred to St. Louis child guidance clinics, it requires a significant history of features of conduct disorder prior to age 15. In addition, antisocial personality disorder is a heavily behavioral diagnosis, with substantial emphasis on explicit antisocial and criminal acts (incidentally, the term "antisocial" should not be confused with "asocial"; the former term refers to committing actions against others, the latter to withdrawing from others). The primary features of antisocial personality disorder, according to DSM-5, are consistent irresponsibility and transgression of social norms and laws, often resulting in multiple arrests; repeated dishonesty; poor impulse control and recklessness; hostility and physical aggressiveness; and lack of guilt. DSM-5 also describes several associated features of antisocial personality disorder, such as deficient empathy, sexual promiscuity, poor work performance, including dishonorable discharges from the military, and parasitism on others.

Perhaps largely because of its ties to engagement in violence toward others, antisocial personality disorder is linked to elevated rates of premature death, especially among men under 40 (Black, Baumgard., \& Bell, 1996). The somewhat lower risk post age-40 may reflect the long discussed "burnout" phenomenon, whereby individuals with this condition display lower levels of antisocial behavior beginning in middle age (Arboleda-Florez, \& Holley, 1991). Antisocial personality disorder co-occurs with a number of other conditions, including borderline and narcissistic personality disorders; individuals with this condition are also at elevated risk for gambling disorder and substance misuse of many kinds (Sher \& Trull, 1994).

Antisocial personality disorder overlaps moderately with another condition with which it is frequently confused (Berg et al., 2013), namely psychopathic personality (psychopathy). In 
Personality Disorders: Scientific Status contrast to antisocial personality disorder, which is characterized by a longstanding history of antisocial and criminal behaviors, psychopathy is operationalized primarily by a constellation of affective (e.g., lack of guilt, lack of empathy), interpersonal (e.g., superficial charm, grandiosity), and behavioral (e.g., dishonesty, poor impulse control) features (Hare, 1991/2003; Lilienfeld, 1994). Numerous film characters, including Alex DeLarge, portrayed by Malcolm McDowell in Stanley Kubrick's brilliant but horrifying, A Clockwork Orange (1971), capture many of the key features of psychopathy; nevertheless, in contrast to DeLarge and contrary to popular misconception, most psychopaths are not violent toward others (Berg et al., 2013). In prison settings, $75 \%$ or more of individuals meet criteria for antisocial personality disorder, whereas only $20-25 \%$ meet research criteria for psychopathy, most often as operationalized by a cut-off score on the Psychopathy Checklist-Revised (Hare, 1991/2003), a well validated interviewbased measure that requires access to corroborative (e.g., file) information. Importantly, contrary to popular (mis)conception, most psychopaths are not violent (Berg et al., 2013). Although psychopathy is not in the main text of DSM-5 and has never formally appeared in the DSM, it now appears for the first time in Section III of DSM-5 as a specifier for antisocial personality disorder. This specifier emphasizes the boldness (e.g., extraversion, attentionseeking) features of psychopathy, which appear to be especially effective in distinguishing this condition from antisocial personality disorder (Venables, Hall, \& Patrick, 2014). Nevertheless, the role of boldness within the psychopathy construct is controversial. Some authors regard it is an important feature of psychopathy (e.g., Lilienfeld et al., in press), one that helps to account for the short-term social success of many psychopathic individuals in politics, business, and other domains (Lilienfeld et al., 2013), whereas others regard it is peripheral or even irrelevant to psychopathy (Miller \& Lynam, 2012).

Antisocial personality disorder appears to be highly heterogeneous, with cluster analyses identifying only one subtype among several corresponding clearly to the classical psychopathy prototype identified by Cleckley (1941), which is marked by a paradoxical 
combination of superficial and low anxiety, on the one hand, and affective poverty, manipulativeness, and poor impulse control, on the other (Poythress et al., 2010). Other subtypes within this diagnosis include what Karpman (1941) termed "secondary psychopathy," which is a disposition toward antisocial behavior that is a consequence of either early environmental disadvantage or emotional distress (Lykken, 1995). Regrettably, in its accompanying text, DSM-5 (American Psychiatric Association, 2013, pp. 659) refers to psychopathy as essentially synonymous with antisocial personality disorder, compounding the confusion between these two constructs.

\section{Prevalence and demographic correlates}

DSM-5 reports that the prevalence of antisocial personality disorder in the general population ranges from $0.2 \%$ to $3.3 \%$. Across studies, the condition is substantially more prevalent among men than women, with rates perhaps 2 to 3 times higher in males (Cale \& Lilienfeld, 2002). There are suggestions that antisocial personality disorder is less prevalent in Asian countries, such as Taiwan, than in Western countries, such as the United States (Cooke, 1996), but the evidence on this front is provisional. Burgeoning data suggest that at least some of the precursors of psychopathy can be identified in childhood. Specifically, a constellation of attributes typically called callous-unemotional (CU) traits, which can be assessed in early childhood and which comprise such attributes as lack of empathy, guiltlessness, absence of strong affective bonds to others, and a lack of concern about one's school performance, are line linked to later psychopathic traits in adolescence (Frick, Ray, Thornton, \& Kahn, 2014).

Nevertheless, the robustness of these findings, and particularly the incremental contribution of CU traits above and beyond aggressiveness, has not gone unquestioned (Lahey, 2014), nor has the construct validity of the CU construct as presently conceptualized (e.g., Berg et al., 2013; Latzman, Lilienfeld, Latzman, \& Clark, 2013).

\section{Potential etiological correlates}


Personality Disorders: Scientific Status

Twin and adoption studies demonstrate that antisocial personality disorder, and chronic antisocial behavior more generally, is moderately heritable. In contrast to most mental disorders, however, antisocial personality disorder also appears to be characterized by a marked shared environmental component (Rhee \& Waldman, 2002), meaning that it is influenced by environmental factors shared within families. Consistent with these findings, individuals with antisocial personality disorder are considerably more likely than other individuals to have histories of early abuse, especially physical abuse (Luntz \& Widom, 1994). Some of this relation may be genetically mediated; for example, the parents of probands with antisocial personality disorder are more likely themselves to be aggressive and to pass on genes predisposing to aggression to their children (DiLalla \& Gottesman, 1991). Nevertheless, studies of monozygotic twins discordant for a history of early maltreatment point to higher rates of antisocial behavior in abused twins, lending credibility to the possibility that such maltreatment is directly causal (Jaffee, Caspi, Moffitt, \& Taylor, 2004).

A growing body of literature has examined potential etiological correlates of psychopathy. Compared with nonpsychopathic individuals, psychopathic individuals tend to display weak electrodermal (skin conductance) classical conditioning to aversive stimuli, weak electrodermal activity in anticipation of electric shock or aversive noise blasts, and poor passive avoidance learning (learning to inhibit responses that have a heightened probability of leading to punishment; see Lykken, 1995, for a review). Consistent with these findings, functional brain imaging studies generally point to amygdala underactivity among psychopathic participants in response to threatening cues, such as facial photographs depicting fear (Blair, Mitchell, \& Blair, 2005). In aggregate, these results suggest that low fear may be one key correlate and perhaps contributor to psychopathy. Other authors have argued, however, that the core deficit in psychopathy is not fearlessness, but response modulation: difficulty in attending to extraneous stimuli in the presence of a potent dominant response set, such as reward (Patterson \& 
Personality Disorders: Scientific Status

Newman, 1993). In contrast, others contend that the research evidence for the response modulation hypothesis is relatively weak (Smith \& Lilienfeld, 2015). The debate continues.

\section{Treatment}

There are no randomized controlled trials of either psychological or psychopharmacological treatments for antisocial personality disorder or psychopathy. This omission is troubling given the enormous social costs inflicted by individuals with the condition. For many decades, prominent scholars and clinicians had long assumed that psychopathy was essentially untreatable (see Salekin, 2002, for a review). Nevertheless, provisional data have begun to call this conventional wisdom into question. For example, naturalistic data on civil psychiatric patients suggest that psychopathic individuals respond as well to intensive inpatient treatment (that is, they display the same reductions in later violence) as do other individuals, and controlled data indicate that adolescents with high scores on psychopathy measures show improvements following intensive cognitive-behavioral therapy (see Skeem et al., 2011, for a review). Nevertheless, these encouraging findings will require verification in additional controlled studies.

Borderline personality disorder

Clinical description and overlap with other conditions

DSM-5 describes borderline personality disorder as marked by "a pervasive pattern of instability of interpersonal relationships, self-image, and affects, and marked impulsivity" (American Psychiatric Association, 2013, p. 663). Indeed, instability is such a hallmark feature of the borderline personality disorder that some authors have referred to it as a condition of "stable instability" (Schmideberg 1959). According to DSM-5, the core features of borderline personality disorder include an unclear sense of identity that often shifts over brief time periods; unstable and tumultuous relationships with others; desperate attempts to avoid rejection or abandonment by others; extreme impulsivity' deep-seated feelings of emptiness; a propensity toward rage; both suicidal and nonsuicidal self-injury; and rapid and dramatic mood shifts, often 
Personality Disorders: Scientific Status

in response to seemingly minor provocations (e.g., a trivial perceived insult from a friend). With respect the lattermost criterion, a precursor to this diagnosis was the Research Diagnostic Criteria (RDC) diagnosis of "labile personality disorder," a condition characterized by extreme instability in mood (see Van Valkenburg, Kluznik, Speed, \& Akiskal, 2006). The character Alex Forrest, portrayed by Glenn Close in the film Fatal Attraction (1987), displays many of the features of borderline personality disorder, although Forrest's extreme violence toward humans and animals is atypical of individuals with the condition. Actress Winona Ryder provided a less dramatic, although probably more realistic, portrayal in the film, Girl, Interrupted (1999), based loosely on the memoir of author Susanna Kaysen.

Borderline personality disorder is tied to marked functional impairment across many life domains, including loneliness and other interpersonal problems (e.g., Paris \& Zeigh-Frank, 2001). Most notable is the increased risk for suicide, which may be as elevated as $10 \%$, or about 50 times the general population prevalence (Bradley, Conklin, \& Westen, 2007). A widespread misconception is that most, if not all, patients with borderline personality disorder engage in self-harming behavior, such as wrist-slashing. Although the rates of such behavior are indeed elevated among patients with the disorder, they do not come close to approaching $100 \%$. Moreover, in a 2006 study of 89 hospitalized adolescents who had engaged in cutting and other forms of nonsuicidal self-injury, Nock, Joiner, Gordon, Lloyd-Richardson, and Prinstein (2006) reported that $48 \%$ did not fulfil DSM criteria for borderline personality disorder; most met criteria for other personality disorders, including avoidant personality disorder.

Borderline personality disorder co-occurs substantially with many other personality disorders, such as schizotypal, paranoid, antisocial, histrionic, avoidant and dependent personality disorders, as well as with other mental disorders, especially major depression and bipolar disorder (Lieb, Zanarini, Schmahl, Linehan, \& Bohus, 2004). In fact, its overlap with other conditions is often so marked that one author team famously referred to borderline as "an adjective in search of a noun" (Akiskal et al., 1985) and another questioned whether borderline 
Personality Disorders: Scientific Status personality disorder can be meaningfully differentiated from histrionic or narcissistic personality disorders, among other personality disorders (Pope, Jonas, Hudson, Cohen, \& Gunderson, 1983). Still other authors contend that the construct validity of borderline personality disorder is supported by evidence of its relative distinctiveness on psychometric indices, such as its 8-4-2 (Schizophrenia, Psychopathic deviate, Depression) pattern on the Minnesota Multiphasic Personality Inventory (Kroll, Sines, Martin, Lari, Pyle, \& Zander, 1981), and evidence for its differentiation from other conditions, such as bipolar disorder (Magill, 2004). At the risk of oversimplifying an extremely large, complex, and at times contradictory body of literature, it seems likely that Akiskal al.'s (1985) now three-decades-old conclusion that borderline personality disorder is a heterogeneous mélange of diverse conditions characterized by high levels of negative emotionality, affective instability, and poor impulse control has stood the test of time. Further research will be needed to clarify the murky boundaries between borderline personality disorder and other mental disorders, presuming that such boundaries exist.

This controversy notwithstanding, there appears to be one point of widespread, if not virtually universal, consensus: The condition is misnamed. The term "borderline," coined by psychoanalyst Adoph Stern (1938) approximately 8 decades ago, reflected the then-prevalent conception that borderline personality disorder lies in the murky boundary between neurosis and psychosis. This conjecture is almost surely incorrect; although individuals with borderline personality disorder are often prone to experiencing transient psychotic episodes under stress (American Psychiatric Association, 2013), longitudinal data do not support the view that they are at heightened risk for later schizophrenia or other psychotic disorders (e.g., Akiskal, 2002). Despite such evidence, the name has stuck. We are inclined to agree with psychologist Marsha Linehan, a pioneer in the field who has courageously and openly discussed her own personal struggles with borderline personality disorder, that a better name for the condition is "emotion dysregulation disorder" (see Lilienfeld \& Arkowitz, 2012). Nevertheless, it remains unclear 
Personality Disorders: Scientific Status

whether this condition constitutes a single disorder as opposed to an umbrella category subsuming several distinct conditions marked by severe emotion regulation difficulties.

One additional noteworthy point of consensus is that borderline personality disorder is almost certainly overdiagnosed in many clinical settings, especially when structured interviews are not used. Some authors have aptly observed that this diagnosis is frequently affixed as a handy term of opprobrium for patients who deemed to be interpersonally difficult or difficult to manage (Vaillant, 1992). It goes without saying that this sloppy diagnostic practice should be avoided, as it can contribute to improper treatment as well as to the unwarranted social stigma already associated with the disorder (Lilienfeld \& Arkowitz, 2012).

Prevalence and demographic correlates

DSM-5 (American Psychiatric Association, 2013) estimates the median prevalence of borderline personality disorder in the general population as $1.6 \%$, but acknowledges that there is considerable variation in prevalence estimates across studies. Its rates in clinical samples tend to be much higher, often approaching $29 \%$ among psychiatric inpatients. Borderline personality disorder is substantially overrepresented among females (Swartz, Blazer, George, \& Winfield, 1990).

\section{Potential etiological correlates}

Psychoanalytic theorists have long traced borderline personality disorder to disturbances in early development. Kernberg (1967) argued, for instance, that in the presence of inadequate parenting, young children may become incapable of integrating good with bad "object" (that is, person) representations, leading to a pervasive propensity called "splitting," in which others are perceived as entirely good or entirely bad rather than as basically good but imperfect people, warts and all (Tomkin \& Fine, 1985). The psychoanalytic concept of splitting, incidentally, should not be confused with its colloquial meaning, which refers to pitting individuals (e.g., staff members, family members) against each other (Lilienfeld, Sauvigne, Lynn et al., 2015). Kernberg's model certainly captures a key descriptive truth: People with borderline personality 
Personality Disorders: Scientific Status

disorder frequently experience wildly unstable views of others. For example, they are notorious for overidealizing (worshipping) certain individuals at one point in time, only to devalue later them when they commit a perceived offense or blunder. At the same time, Kernberg's model has proven difficult to test given its substantial reliance on unconscious and arguably unmeasurable processes.

Linehan's influential biosocial model of borderline personality disorder (see Crowell, Beachaine, \& Linehan, 2009) posits that this condition is induced by a complex set of developmental transactions between genetic vulnerabilities to emotional dysregulation and psychosocial factors, particularly an invalidating environment provided by parents and others. Preliminary evidence supports at least some features of this model. In particular, twin studies indicate that borderline personality disorder is at least moderately genetically influenced, although the magnitude of heritability varies substantially across studies, perhaps reflecting the heterogeneity of this condition (Crowell et al., 2009). Also supporting this model, individuals with borderline personality disorder retrospectively report elevated rates of childhood sexual and physical abuse (Bradley et al., 2007). Nevertheless, data from a study of monozygotic identical twins discordant for borderline personality disorder, a design that allows investigators to control for genetic influences, found little or no evidence for a direct causal effect of trauma, including early emotional, sexual, or physical abuse, on later borderline personality disorder traits (Bornovolava et al., 2013). These findings raise the possibility that previously reported links between early trauma and later borderline personality disorder reflect unmeasured third variables, such as genetically influenced personality dispositions.

A large body of research has examined interpersonal and emotional processing deficits in individuals with the condition. For example, individuals with borderline personality disorder tend to perceive others negatively and to interpret ambiguous social interactions as threatening (Lazarus, Cheavens, Festa, \& Rosenthal, 2014). This conclusion is buttressed by functional brain imaging data indicating that people with this condition tend to exhibit amygdala overactivity 
Personality Disorders: Scientific Status

when judging others' emotions (Mier et al., 2013; Rosenthal et al, 2008). Several studies also point to deficiencies in cognitive empathy ("theory of mind") among individuals with borderline personality disorder, although this body of literature is not entirely consistent (Lazarus et al., 2014). In addition, individuals with borderline personality disorder consistently display deficits on social problem-solving tasks. For example, when confronted with a hypothetical interpersonal problem, such as how to respond when a boyfriend or girlfriend keeps staring at other attractive persons while they are out on dates, individuals with borderline personality disorder are more likely than other individuals to select a passive solution, such as acting in a sullen or aloof manner toward their boyfriend or girlfriend (Kremers, Spinhoven, Van der Does, \& Van Dyck, 2006). Further research will be necessary to clarify how, if at all, these diverse deficits interrelate as well their etiological linkages, if any, to the core affective, cognitive, and behavioral features of the condition.

\section{Treatment}

A large body of literature, too vast to review here in depth, has appeared on the psychological treatment of borderline personality disorder. By far the most widely studied - and best validated intervention - for the condition is dialectical behavior therapy (DBT), originally developed by Linehan (1987) as a treatment for suicidal individuals with the condition but later extended to borderline personality disorder more broadly. DBT, informed by tenets of both Buddhism and cognitive-behavioral therapy, is "dialectical" in that it encourages patients to both accept their feelings (e.g., anger, desperation) while recognizing that these feelings are ultimately maladaptive and need to be replaced by healthier emotions. DBT is an exceedingly complex, multicomponent procedure, making it difficult to ascertain which aspects of the treatment are efficacious, either in isolation or in interaction with each other. Many of its central techniques involve teaching patients coping skills to tamp down and de-escalate their destructive emotions. Meta-analyses suggest that DBT is moderately efficacious for borderline personality disorder, both overall and for its associated suicidal and other self-harm behaviors 
Personality Disorders: Scientific Status

(Kliem, Kröger, \& Kosfelder, 2010). Nevertheless, it is unclear whether DBT is more efficacious for borderline personality disorder compared with other established treatments, such as standard cognitive-behavioral therapy or structured psychodynamic therapy (Clarkin, Levy, Lenzenweger, \& Kernberg, 2007). Although selective serotonin reuptake inhibitors are widely prescribed for borderline personality disorder (Knappich, Hörz-Sagstetter, Schwerthöffer, Leucht, \& Rentrop, 2014), controlled studies provide weak or even negligible support for their efficacy in this regard (Lieb et al., 2010).

Histrionic personality disorder

Clinical description and overlap with other conditions

DSM-5 describes histrionic personality disorder as marked by 'pervasive and excessive emotionality and attention-seeking behavior" (American Psychiatric Association, 2013; p. 667). Tracing its roots to the older psychodynamic concept of the "hysterical personality" (Smith \& Lilienfeld, 2012), histrionic personality disorder is characterized by such features as needing to be in the center of attention in social situations; seductiveness; overly flamboyant behavior; and regarding friendships as more intimate than they are. The dramatic behavior often observed in this disorder inspired the name "histrionic," after the Latin histrionicus, referring to an actor. Because they tend to use their physical appearance to draw attention to themselves, many individuals with histrionic personality disorder spend an excessive amount of resources on fashion and grooming. Their language is often vague and generalized, and marked by strong opinions devoid of much specificity, a style often referred to as hyperbolic speech (e.g., "That movie was incredibly wonderful," "He was an absolutely horrible boyfriend"; see Shapiro, 1965). As associated features, DSM-5 notes that histrionic personality disorder is often characterized by difficulties with romantic relationships. Their relationships often lack genuine emotional intimacy, and their seductiveness may coexist with a tendency to find romantic relationships unsatisfying. They frequently believe that they have been victimized in relationships and friendships, although outside observers often regard them as bringing their mistreatment upon 
Personality Disorders: Scientific Status

themselves. In some cases, individuals with this condition may make suicidal gestures and threats for attention. The character of Scarlett O'Hara, portrayed by Vivien Leigh in the Gone with the Wind, captures many or most of the classic features of histrionic personality disorder.

Not surprisingly given its associations with impulsive and dramatic behaviors, including parasuicidal actions, histrionic personality disorder overlaps substantially with borderline personality disorder (Oldham et al., 1992). For reasons that are not well-understood, individuals with this condition are also at heightened risk of unexplained somatic symptoms (Lilienfeld, Van Valkenberg, Larntz, \& Akiskal, 1986), reinforcing its longstanding historical ties to hysteria (formerly called somatization disorder or Briquet's syndrome; see Blagov, Fowler, \& Lilienfeld, 2007, for a review).

\section{Prevalence and demographic correlates}

The prevalence of histrionic personality disorder in the general population has been estimated by be approximately 2\% (American Psychiatric Association, 2013). Although the condition tends to be considerably more prevalent in females in clinical samples, most general population studies reveal few or no sex differences (Blagov et al., 2007). The reason for this discrepancy is unclear, although it is possible that the higher levels of depression and suicidal behavior among women with histrionic traits boost their likelihood of seeking out treatment.

\section{Potential etiological correlates}

Few studies have examined the etiology of histrionic personality disorder. One twin study revealed a heritability of histrionic personality disorder of between. 52 and .67 , depending on the statistical model selected (Torgeson et al., 2000). A retrospective study of parenting practices experienced by individuals with the disorder in childhood revealed higher rates of exposure to controlling parenting styles than among healthy comparison participants (Baker, Capron, \& Azorlosa, 1996), although this difference may be colored in part by differences in recall. Regarding more proximal etiological variables, a number of authors have conjectured that individuals with this condition are prone to a global cognitive style (Shapiro, 1965) marked an 
undue focus on the "big picture" and a neglect of details. Nevertheless, the admittedly limited laboratory evidence for this conjecture is weak (Sacco \& Olczak, 1996); moreover, even were this conjecture to be empirically supported, it is unclear whether it helps to explain as opposed to merely describe the clinical picture of histrionic personality disorder.

Treatment

There are no controlled psychological or pharmacological intervention studies on histrionic personality disorder.

Narcissistic personality disorder

Clinical description and overlap with other conditions

DSM-5 describes narcissistic personality disorder as marked by "a pervasive pattern of grandiosity (in fantasy or behavior), need for admiration, and lack of empathy" (American Psychiatric Association, 2013, p. 669). Its key features include an excessive sense of selfimportance; arrogance; preoccupation with achieving great successes in life; a belief that one is unique and can only be understood and appreciated by other extremely special people; taking advantage of others; callousness; and entitlements, that is, beliefs that one deserves special favors that others do not (e.g., finding it outrageous than one cannot be seated in a crowded restaurant before other, "lesser," people). Deriving its name from the Greek character Narcissus, who fell in love with his own reflection in a pool and die after staring at it, narcissism and its associated personality disorder are marked by extreme self-focus and self-admiration to the point that they interfere with interpersonal functioning.

Associated features in DSM-5 include extreme levels of ambition and achievementstriving, as well as excessive vulnerability to minor perceived slights. The latter trait has been broadly corroborated by laboratory research demonstrating that individuals with marked narcissistic traits, but not those with high self-esteem, are likely to retaliate aggressively (e.g., by delivering aversive noise blasts) against those who have criticized them (Bushman \& Baumeister, 1998). The character of Charles Foster Kane, portrayed brilliantly by Orson Welles 
Personality Disorders: Scientific Status

in the landmark American film Citizen Kane (1941), exhibits many of the features of narcissistic personality disorder (Kane's character was based loosely on that of newspaper magnate William Randolph Hearst).

Narcissistic personality disorder covaries with several other personality disorders, including other Cluster B disorders and schizotypal personality disorder. In addition, elevated rates of narcissistic personality have been reported in other mental disorders, including bipolar disorder (Ronningstam, 1996; Stinson et al., 2008) and perhaps anorexia nervosa (American Psychiatric Association, 2013). Data suggest that narcissistic personality disorder is linked to a number of negative life outcomes, including long-term depression and dissatisfaction in sexual relationships (Plakun, 1989). Nevertheless, most evidence indicates that the disorder engenders impairment primarily by engendering distress in others rather than in affected individuals themselves (Miller, Campbell, \& Pilkonis, 2007).

Factor analyses suggest that measures of narcissism are heterogeneous, and can be subdivided into two dimensions that are only modestly correlated: grandiose (overt) and vulnerable (covert; Wink, 1991). Individuals with elevated levels of grandiose narcissism, like those of such politicians as Benito Mussolini, are flamboyant and boastful, whereas those with elevated levels of vulnerable narcissism, like those of many of the characters portrayed by comedian Woody Allen in his films, are oversensitive to criticism and self-focused. DSM narcissistic personality disorder appears to be a blend of both dimensions, albeit with a heaver representation of grandiose narcissism (Miller, Gentile, Wilson, \& Campbell, 2013). These two dimensions, which are conflated in the DSM diagnosis, are crucial to distinguish given that they display substantially different correlates. For example, grandiose narcissism is positively correlated with extraversion and negatively correlated with neuroticism, whereas vulnerable narcissism is positively correlated with neuroticism; both dimensions are positively associated with antagonism (low agreeableness), although the association with grandiose narcissism is more marked (Miller et al., 2011). 


\section{Prevalence and demographic correlates}

DSM-5 reports a wide range of prevalence estimates (from $0 \%$ to $6.2 \%$ ) in general population samples. Nevertheless, the lion's share of studies points to a median prevalence of slightly under 1\% (Levy, Reynoso, Wasserman, \& Clarkin, 2007). Most studies suggest a modest male predominance in rates of the disorder (American Psychiatric Association, 2013). Although the disorder appears to be relatively rare in most clinical samples - presumably because the condition tends to be largely ego-syntonic - it may be more prevalent in private practice settings (Levy et al., 2007). In such settings, individuals with narcissistic personality disorder may obtain treatment because others (e.g., spouses) insist that they do so or because they experience distress arising from their perception that others do not sufficiently appreciate them.

A number of studies suggest that that the levels of narcissism in the U.S. population, especially among young adults, have been rising in recent decades (Twenge, Konrath, Foster, Campbell, \& Bushman, 2008), although this conclusion has been contested by some authors (Trzesniewski \& Donnellan, 2010). The extent to which these reported secular trends apply to narcissistic personality disorder as opposed to trait narcissism is unclear.

\section{Potential etiological correlates}

Most of the writing on the etiology of narcissistic personality disorder derives from psychoanalytic theorists. Kohut (1966), for example, argued that this disorder stems from insufficient "mirroring" from parents and other significant figures in early life. According to him, all children require admiration and idealization. When these needs go unmet, the resulting pathological narcissism in adults reflects a compensatory effort to boost self-esteem. More broadly, most psychoanalytic thinkers have argued that extreme narcissism is an unconscious defense against deep-seated feelings of low self-esteem, a conjecture buttressed by the fact that many narcissistic individuals, especially those with vulnerable narcissism, tend to be brittle and thin-skinned. Nevertheless, research using implicit measures, such as the Implicit 
Personality Disorders: Scientific Status

Association Test, have not consistently supported the view that narcissistic individuals suffer from latent low self-esteem (Campbell, Bosson, Goheen, Lakey, \& Kernis, 2007).

Narcissistic personality disorder appears to be substantially generically influenced, perhaps even more so than most other personality disorders; data from one twin study point to a heritability of .79 (Torgeson et al., 2010). Retrospective data point to differences in early parenting, or at least early perceived early parenting, in individuals with certain narcissistic traits. In particular, undergraduates with high levels of vulnerable, but not grandiose, narcissism report elevated rates of parental abuse and neglect, as well as lower parental warmth and higher parental intrusiveness, compared with other undergraduates (Miller, Dir, Gentile, Wilson, Pryor, \& Campbell, 2010). The extent to which these findings reflect direct environmental causation as opposed to biases in retrospective reporting or the influence of undetected third variables requires clarification.

Treatment

There are no controlled psychological or pharmacological intervention studies on narcissistic personality disorder. Subgroup analyses in one naturalistic (non-controlled) study suggest that client-centered (Rogerian) psychotherapy, which emphasizes self-acceptance, may alleviate depression in individuals with narcissistic personality disorder (Teusch, Bohme, Finke, \& Gastpar, 2001), although these observations are provisional and warrant replication in controlled investigations.

\section{Cluster C: The anxious, fearful cluster}

Avoidant personality disorder

Clinical description and overlap with other conditions

DSM-5 describes dependent personality disorder as marked by "a pervasive pattern of social inhibition, feelings of inadequacy, and hypersensitivity to negative evaluation" (American Psychiatric Association, 2013, p. 673). Its key diagnostic characteristics include a reluctance to 
Personality Disorders: Scientific Status

enter into friendships or relationships unless there is a virtual unconditional guarantee of approval; pronounced fears of rejection from others; avoidance of occupational activities involving contact with others because of apprehension of disapproval; and avoidance of trying new things out of fear of making a fool of oneself in public. As associated features, DSM-5 notes that individuals with this condition are frequently described as shy and lonely, and are commonly hypervigilant to cues of potential rejection in interpersonal situations.

Avoidant personality disorder overlaps substantially with a number of other personality disorders, especially dependent personality disorder. It also overlaps considerably with social anxiety disorder (social phobia), so much so that many scholars have questioned whether the two are distinct conditions (Herbert, 2007). Indeed, in some samples, the overlap is as high as $88 \%$ or even $100 \%$ (Weinbrecht, Schule, Boettcher, \& Renneberg, 2016). The research here continues be a flashpoint of contention, but most data suggest that the two conditions are extremely similar, but that avoidant personality disorder is characterized by somewhat greater social anxiety, as well as impairment in social skills and relationship functioning (Turner, Beidel, Dancu, \& Keys, 1986; Weinbrecht et al., 2016; but see Herbert, Hope, \& Bellack, 1992).

\section{Prevalence and demographic correlates}

DSM-5 places the prevalence of avoidant personality disorder at approximately $2.5 \%$, with approximately equal rates in men and women (American Psychiatric Association, 2013).

\section{Potential etiological correlates}

A study of female twins suggested moderate heritability for avoidant personality disorder, along with considerable genetic overlap between this condition and social phobia (ReichbornKjennerud, 2007). Data suggest that the emergence of anxiety disorders in childhood and adolescent are risk factors for the emergence of later avoidant personality disorder (Weinbrecht et al., 2016), consistent with the possibility that these conditions reflect a shared diathesis, perhaps toward negative emotionality. Retrospective studies suggest that individuals with avoidant personality disorder tend to recall their parents as having been more shame-inducing, 
concerned with social evaluation, and critical than do other individuals (see Herbert, 2007, for a review). As always, however, the extent to which these findings reflect environmental as opposed to genetic factors is unclear; for example, it is possible that they at least partly reflect the influence of genetically influenced personality traits, such as negative emotionality (which it

tied to a propensity to perceive one's past experiences in a more negative light; Watson \& Clark, 1984).

\section{Treatment}

Several controlled studies suggest that cognitive-behavioral treatments, especially those incorporating social skills training and behavioral rehearsal, are efficacious for avoidant personality disorder (e.g., Renneberg, Goldstein, Phillips, \& Chambless, 1990). This broad class of interventions also appears to be beneficial when administered in a group format (Weinbrecht et al., 2016); such a format may itself afford a vehicle for exposure therapy among individuals with elevated levels of social anxiety. Although some authors have reported promising results for avoidant personality disorder with monoamine oxidase inhibitors or selective serotonin reuptake inhibitors (e.g., Delitoto \& Stam, 1989), little or no systematic controlled data support their use for this purpose.

Dependent personality disorder

Clinical description and overlap with other conditions

DSM-5 describes dependent personality disorder as marked by "a pervasive and excessive need to be taken care of that leads to submissive and clinging behavior and fears of separation" (American Psychiatric Association, 2013; p. 675). Its key diagnostic criteria include difficulties with making ordinary decisions without help from others; asking others to take over responsibility for major life activities; reluctance to voice disagreements with others; unwillingness to undertake and carry out projects independently; and "clinginess" in interpersonal relationships. As associated features, DSM-5 notes that individuals with this condition are characterized by excessive doubts of themselves and may perceive themselves 
Personality Disorders: Scientific Status

as inept. Although dependent personality disorder overlaps substantially with other Cluster C personality disorders, it also displays pronounced overlap with borderline and histrionic personality disorders (e.g., Tomko et al. 2014). Traits of this condition are associated with agoraphobic avoidance among patients with panic disorder (Reich, Noyes, \& Troughton, 1987), perhaps because such traits contribute to a reluctance to venture out independently in social situations. It is also possible, however, that the causal arrow is reversed, and that agoraphobic avoidance contributes to interpersonal dependency, consistent with the complication/scar model discussed earlier (De Bolle et al., 2012).

Prevalence and demographic correlates

The prevalence of dependent personality disorder in the general population has been estimated to be approximately .5\% (American Psychiatric Association, 2013), making it one of the rarest of the DSM personality disorders. A meta-analysis of epidemiological studies by Bornstein (1997) revealed a $40 \%$ higher prevalence of this condition in women than in men.

\section{Potential etiological correlates}

There are few leads to the etiology of dependent personality disorder. Twin research suggests that approximately $30 \%$ of the variance in dependent personality disorder features is heritable (Torgeson et al, 2000). Data suggest that both overprotective ("helicopter") and authoritarian parenting styles are associated with elevated risk for dependent personality disorder (Bornstein, 2007; Head, Baker, \& Williamson, 1991). Nevertheless, these findings may in part reflect passive or evocative (reactive) gene-environment correlations rather than direct environmental causality. In the case of the former, overprotective parents may themselves be highly dependent, and pass on genetically influenced personality traits predisposing to dependency to their children; in the case of the latter, parents may react to highly dependent children by imposing high demands on, or distancing themselves from, them.

Treatment 
Personality Disorders: Scientific Status

There are no controlled psychological or pharmacological intervention studies on dependent personality disorder.

Obsessive-compulsive personality disorder

Clinical description and overlap with other conditions

DSM-5 describes obsessive-compulsive personality disorder as marked by "a preoccupation with orderliness, perfectionism, and mental and interpersonal control, at the expense of flexibility, openness, and efficiency" (American Psychiatric Association, 2013, p. 679). The core features of this condition are similar to Freud's (1908) classic description of the anal triad of obstinacy (stubbornness), parsimony (cheapness), and orderliness. Although Freud's etiological supposition that anal personality traits stem from overly strict toilet training was almost surely incorrect, his clinical description has broadly stood the test of time. As DSM5 observes, individuals with this condition tend to be preoccupied with minor details, lists, and other minutia; perfectionistic to the point that tasks are often left uncompleted; hypermoralistic and inflexible regarding ethical manners (e.g., an academic colleague might berate a fellow faculty member for bringing home a pen or paper-clip from his workplace); rigid with respect to planning and decisions (e.g., insisting that every detail of a vacation be carefully choreographed well in advance); miserly with regard to spending; and unwilling to delegate tasks to others. As associated features, DSM-5 notes that individuals with this condition are prone to righteous indignation over relatively minor matters, and that they often experience difficulties expressing warmth to friends and romantic partners. The incurably punctilious but lovable character of Felix Ungar, portrayed by Tony Randall in the popular television 1970s series, The Odd Couple, embodies many of the features of this condition.

As noted earlier, the ties between obsessive-compulsive personality disorder and psychosocial functioning have been inconsistent. Although some studies point to impairment in the interpersonal realm, at least some suggest superior work performance and educational attainment, as well as greater income (Samuel \& Griffin, 2012); as every graduate student is 
Personality Disorders: Scientific Status

aware, working long hours and attending to details have their upsides. In this respect, obsessive-compulsive personality disorder may be unique among personality disorders in being tied to better than average performance in at least some important life domains. At the same time, this work ethic almost certainly has its costs, as evidence points to empirical linkages between obsessive-compulsive traits, especially those tied to stubbornness and moral scrupulousness, and workaholism (Mudrack, 2004). Although obsessive-compulsive personality disorder is statistically associated with obsessive compulsive disorder, the degree of overlap is only moderate (Coles et al., 2008; Samuel \& Griffin, 2012). Obsessive-compulsive personality disorder also appears to overlap partially with the new DSM-5 (American Psychiatric Association, 2013) diagnosis of hoarding disorder.

Prevalence and demographic correlates

DSM-5 estimates the prevalence of obsessive-compulsive personality disorder in the general population to be between 2 and $8 \%$; the reasons for this wide prevalence range are unclear. The condition appears to be approximately twice as common among males as females.

\section{Potential etiological correlates}

Obsessive-compulsive personality disorder tends to be moderately influenced by genetic factors, with heritability estimates derived from twin studies ranging from $46 \%$ percent for males to $62 \%$ for females (Nigg \& Goldsmith, 1994). Although some evidence suggests that parents of individuals with the disorder tend to be inflexible and demanding, it is unclear that this finding reflect shared environmental as opposed to genetic influences given that it derives from studies of intact families (Bartz, Kaplan, \& Hollander, 2007). Consistent with the assertion that people with this condition tend to "see the trees rather than the forest" (Shapiro, 1965), laboratory evidence indicates that individuals with marked levels of obsessive-compulsive personality disorder traits exhibit a "local "rather than a "global" cognitive processing style. For example, when presented with a large letter "H" composed of many little "Ts," people with such traits are 
Personality Disorders: Scientific Status

slower than other people to identify the large letter, presumably because they are distracted by the small letters comprising it (Yovel, Revelle, \& Mineka, 2005).

Treatment

Although there is scant treatment research on obsessive-compulsive personality disorder, one controlled study suggested superior outcomes for interpersonal therapy as opposed to cognitive therapy among depressed patients meeting criteria for the disorder (Barber \& Muenz, 1996). Although a number of medications, such as selective serotonin reuptake inhibitors and anticonvulsants, are commonly prescribed for obsessive-compulsive disorder, there are no randomized controlled trials examining their efficacy (Bartz et al., 2007).

\section{Future Directions}

Our view of the current scientific status of the personality disorders field from 35,000 feet yields a confusing and often contradictory picture. On the one hand, the study of personality disorders has advanced considerably since the full-fledged appearance of a personality disorders section on its independent axis in DSM-III in 1980 (American Psychiatric Association, 1980). Throughout that time, our understanding of how abnormal and normal personality interrelate has also evolved, and we now possess a much richer appreciation of how normal-range personality traits, such as those of five-factor and three-factor models, map into personality disorders (Widiger \& Trull, 2007).

On the other hand, it is troubling how little the current classification of personality disorders in the DSM (American Psychiatric Association, 2013) has progressed over the past three and a half decades. Yes, the Axis I-Axis II distinction has been wisely abandoned, we have gone from 11 to 10 personality disorders, the criterion sets for these conditions are now considerably more monothetic, and certain problematic diagnostic criteria have been revised or removed. If the truth be known, however, most of these revisions have been relatively cosmetic. Much of the substantial and hard-won scientific progress that has been achieved in the personality trait domain (e.g., Watson, Clark, \& Harkness, 1994; Clark, 2007; Widiger, 2011; 
Personality Disorders: Scientific Status

Widiger, Livesley, \& Clark, 2009) appears to have been largely neglected across progressive DSM classifications. Furthermore, despite repeated revisions of the personality disorders section of the DSM, many of its systemic problems, such as high levels of diagnostic cooccurrence, large numbers of not otherwise specified cases, and excessive phenotypic and probably etiological heterogeneity, remain (e.g., Clark, 2007). It seems likely, if not inevitable, that without a major overhaul of the classification of personality disorders, these deep-seated flaws will persist in future DSM editions. To our eyes, such an overhaul is not merely warranted, but necessary. Although the precise nature of this sea-change awaits clarification, it has become increasingly clear that it will require the incorporation of a dimensional model for most personality disorders, a direction recognized as necessary more than two decades ago by Allen Frances (1993), Chair of the DSM-IV Taskforce.

We close with a brief discussion of future directions in personality disorder research. In the spirit of being constructive, we focus on two directions that we regard as especially promising and as dovetailing with the increasing emphasis on dimensional models of personality.

Research Domain Criteria (RDoC)

In response to the growing realization that the present DSM system is problematic, in 2009 the National Institute of Mental Health (NIMH) launched a bold initiative to transform psychiatric classification and diagnosis. Termed the Research Domain Criteria (RDoC), this new endeavor aims to describe, and ultimately understand, psychopathology in terms of dimensional variation in brain-based circuitry (Cuthbert \& Insel, 2013; Sanislow et al., 2010). To do so, it draws on research on basic human and non-human animal models of brain-based systems relevant to adaptation and maladaptation (Latzman \& Hopkins, 2016). RDoC is a long-term research program, not a full-fledged classification system in its own right. Hence, it is not an alternative to the DSM, although it may one day yield the rough outlines of a system that will supplant or at least supplement it. 
Personality Disorders: Scientific Status

Many of the RDoC proposed systems are relevant to personality, both normal and abnormal. For example, RDoC encourages investigators to identify promising markers of positive and negative valence brain systems, the former including such subsystems as approach motivation and initial responsivity to reward, and the latter including such subsystems as acute threat (fear) and potential threat (anxiety). These markers, in turn, can be drawn from multiple levels of analysis, such as functional or structural brain imaging, autonomic psychophysiology, laboratory tasks, behavioral observations, or self-reports. The goal is to better characterize brain-based systems and subsystems relevant to both healthy and unhealthy adaptation, the latter presumably relevant to many personality disorders. RDoC is explicitly transdiagnostic in that its aim is to better map out and understand dimensionally-distributed systems and subsystems that cut across DSM categories.

As of this writing, it is far too early to gauge the degree of RDoC's success (Lilienfeld \& Treadway, 2016). On the positive side, RDoC has already helped to loosen the hegemony of the DSM over psychopathology research, including research on normal personality. Nevertheless, some critics have voiced legitimate concerns that RDoC is pushing psychopathology research in too biological a direction, and that RDoC accords insufficient emphasis to developmental and environmental influences on behavior (Berenbaum, 2013). Still others have expressed the worry that RDoC, even if largely successful, will ultimately provide a classification system of biological predispositions toward psychopathology, not a classification system of psychopathology per se (Lilienfeld, 2014; Lilienfeld \& Treadway, 2016). Returning to the distinction between basic tendencies and characteristic adaptations, RDoC may be better suited to understanding the biological correlates of the basic tendencies (e.g., sensitivity to acute threat) relevant to normal and abnormal personality than to understanding how these basic tendencies manifested themselves in characteristic adaptations, including that clinically important subset of maladaptive characteristic adaptations that we call personality disorders. 
Personality Disorders: Scientific Status

All of that said, RDoC is certainly worth a try (Lilienfeld \& Treadway, 2016). At the very least, it is likely that RDoC will contribute to a deeper understanding of how individual differences in the functioning of brain-based adaptive systems predispose to individual differences in personality variables that are relevant to psychopathology. Out of that understanding may one day arise both a clearer picture of these brain-based systems and more sensitive and specific methods of detecting variation in them (see also Harkness, Reynolds, \& Lilienfeld, 2015).

Interpersonal models redux

As burgeoning data point to close empirical linkages between normal and abnormal personality, the field increasingly finds itself confronted with a vexing question that seems rarely to have been asked: Is the time approaching for us to abandon the study of personality disorders as a distinct discipline? After all, if most or even all personality disorders are constellations of extremes on one or more personality traits, should not the field of personality disorders merely merge with normal personality psychology (see Lilienfeld et al., 2014)?

This uncomfortable question does not lend itself to a straightforward answer. At the same time, it is clear that complete abandonment of the personality disorders field to would be premature. Many or most personality disorders, such as paranoid, histrionic, narcissistic, psychopathic, and obsessive-compulsive personality disorders, reflect powerful folk concepts (Gough, 1965) going back at least to Theophrastus that are salient to us in everyday life (see also Miller \& Lynam 2013). Many of these disorders, we contend, are conditions of interpersonal impact (Lilienfeld et al.., 2014), that is, additive combinations or more provocatively, multiplicative interactions of personality traits that eventuate in powerful interpersonal consequences. In this regard, the field of trait psychology and interpersonal psychology may have much to offer one another.

Although FFM advocates have made substantial progress in mapping normal-range personality traits onto personality disorders (e.g.., Lynam \& Widiger, 2001; Saulsman \& Page, 
Personality Disorders: Scientific Status 2004), the personality field at large appears to have displayed scant interest in the crucial question of why only certain configurations of personality traits and personality trait facets are perceived as pathological. Why, out of the thousands of potential configurations of all FFM facets, are only a small number apparently linked to identifiable personality pathology? The answer, we suspect, is that certain configurations, but not others, engender pronounced interpersonal sequelae. For example, we have elsewhere proposed that psychopathy is a distinctive configuration of at least two seemingly contradictory sets of traits, one associated with superficial charm, self-confidence, and low anxiety (boldness) and the other associated with affective detachment, lack of guilt, and weak empathy (coldness); in some individuals, especially those often described as unsuccessful psychopaths, the latter trait complex may be conjoined with poor impulse control (disinhibition). This interpersonally confusing configuration of traits, which maps onto the familiar folk concept of the wolf in sheep's clothing, the con-artist, the social chameleon, and the two-faced person, is potentially dangerous, because it is linked to the ideal recipe for deception: the person who superficially appears trustworthy but who cannot be trusted (Lilienfeld et al., 2014).

Although space precludes a further analysis of this argument here, we suspect that many - although perhaps not all (e.g., schizotypal) - other consensual personality disorders similarly reflect conditions of interpersonal impact. If so, interpersonal theorists may have captured a crucial truth in hypothesizing that personality disorders reflect maladaptive statistical interactions between or among continuously distributed trait dimensions of social import (Grove \& Tellegen, 1991). And if so, the current DSM-5 Section III personality disorders model (American Psychiatric Association, 2013), although an unhappy compromise between advocates of competing camps, may similarly have touched on a crucial truth. Specifically, this alternative model acknowledges the dimensionality of most personality disorders while recognizing that these diagnoses capture prototypes of great interpersonal significance. 
Personality Disorders: Scientific Status

These are times of dissension in the personality disorders field, but they are also exciting times. The accumulating anomalies of the DSM personality disorders system are harbingers of a major change - dare we call it a revolution - ahead. There is growing reason for hope that this change will be at last be grounded in the science of basic personality psychology. Indeed, it ought to be.

\section{References}

Akiskal, H. S., Chen, S. E., Davis, G. C., Puzantian, V. R., Kashgarian, M., \& Bolinger, J. M. (1985). Borderline: An adjective in search of a noun. Journal of Clinical Psychiatry, 46, 41-48. 
Personality Disorders: Scientific Status

Alegria, A. A., Blanco, C., Petry, N. M., Skodol, A. E., Liu, S. M., Grant, B., \& Hasin, D. (2013). Sex differences in antisocial personality disorder: Results from the National Epidemiological Survey on Alcohol and Related Conditions. Personality Disorders: Theory, Research, and Treatment, 4, 214-222.

Amador, X. F., \& Gorman, J. M. (1998). Psychopathologic domains and insight in schizophrenia. Psychiatric Clinics of North America, 21, 27-42.

American Psychiatric Association (1980). Diagnostic and statistical manual of mental disorders, third edition (DSM-III). Washington, D.C.: Author.

American Psychiatric Association (1987). Diagnostic and statistical manual of mental disorders, third edition, reivsed (DSM-III-R). Washington, D.C.: Author.

American Psychiatric Association (2000). Diagnostic and statistical manual of mental disorder, fourth edition, text revision (DSM-IV-TR). Washington, D.C. Author.

American Psychiatric Association (2013). Diagnostic and statistical manual of mental disorders, fifth edition (DSM-5). Washington, D.C.: Author.

Arboleda-Florez, J., \& Holley, H. L. (1991). Antisocial burnout: An exploratory study. Journal of the American Academy of Psychiatry and the Law Online, 19, 173-183.

Barber, J. P., \& Muenz, L. R. (1996). The role of avoidance and obsessiveness in matching patients to cognitive and interpersonal psychotherapy: empirical findings from the treatment for depression collaborative research program. Journal of Consulting and Clinical Psychology, 64, 951-958.

Berenbaum, H. (2013). Classification and psychopathology research. Journal of Abnormal Psychology, 122, 894-901.

Berg, J., Lilienfeld, S. O., Reddy, S., Latzman, R. D., Roose, A., Craighead, L. W., Pace, T. W. W., \& Raison, C. L. (2013). The Inventory of Callous and Unemotional Traits: A constructvalidation analysis in an at-risk sample. Assessment, 20, 532-544 
Personality Disorders: Scientific Status

Berg, J. M., Smith, S. F., Watts, A. L., Ammirati, R., Green, S. E., \& Lilienfeld, S. O. (2013). Misconceptions regarding psychopathic personality: implications for clinical practice and research. Neuropsychiatry, 3, 63-74.

Berkson, J. (1946). Limitations of the application of fourfold table analysis to hospital data. Biometrics Bulletin, 2, 47-53.

Berman, M. E., Fallon, A. E., \& Coccaro, E. F. (1998). The relationship between personality psychopathology and aggressive behavior in research volunteers. Journal of Abnormal Psychology, 107, 651-658.

Bierer, L. M., Yehuda, R., Schmeidler, J.,Mitropoulou, V., New, A. S., Silverman, J. M., et al. (2003). Abuse and neglect in childhood: Relationship to personality disorder diagnoses. CNS Spectrums, 8, 737-754.

Black, D. W., Baumgard, C. H., \& Bell, S. E. (1996). Death rates in 71 men with antisocial personality disorder: a comparison with general population mortality. Psychosomatics, 37(2), 131-136.

Blagov, P.S., Fowler, K.A., \& Lilienfeld, S.O. (2007). Histrionic personality disorder. In W. O'Donohue, S. O. Lilienfeld, and K. A. Fowler (Eds.), Personality disorders: Toward DSM-V (pp. 203-232). Thousand Oaks, CA: Sage Press.

Blair, J., Mitchell, D., \& Blair, K. (2005). The psychopath: Emotion and the brain. Malden, MA: Blackwell Publishing.

Blashfield, R. K., \& Intoccia, V. (2000). Growth of the literature on the topic of personality disorders. American Journal of Psychiatry, 157, 472-473.

Block, J. (1995). A contrarian view of the five-factor approach to personality description. Psychological bulletin, 117, 187-215.

Bogg, T., \& Roberts, B. W. (2004). Conscientiousness and health-related behaviors: A metaanalysis of the leading behavioral contributors to mortality. Psychological Bulletin, 130, 887-919 
Personality Disorders: Scientific Status

Bollini, A.M., Walker, E.F (2007). Schizotypal personality disorder. In W.T. O'Donohue, K.A. Fowler, \& S.O. Lilienfeld (Eds.). Personality Disorders: Toward the DSM V (pp. 81-108). Thousand Oaks: Sage Publications.

Bornovalova, M. A., Huibregtse, B. M., Hicks, B. M., Keyes, M., McGue, M., \& lacono, W. (2013). Tests of a direct effect of childhood abuse on adult borderline personality disorder traits: a longitudinal discordant twin design. Journal of Abnormal Psychology, 122, 180-194.

Bornstein, R. F. (1997). Dependent personality disorder in the DSM-IV and beyond. Clinical Psychology: Science and Practice, 4, 175-187.

Bornstein, R..F,.\& Useda, J.D. (2007). Dependent personality disorder. In O'Donohue, W.T., Fowler, K.A., \& Lilienfeld, S.O. (Eds.). Personality Disorders: Toward the DSM V (pp. 42-63). Thousand Oaks: Sage Publications

Bradley, R., Conklin, C.Z., \& Westen, D. (2007). Borderline personality disorder. In O'Donohue, W., Fowler, K.A., \& Lilienfeld, S.O. (Eds.), Sage Handbook of Personality Disorders (pp. 167201). Thousand Oaks, California: Sage Publications.

Bronisch, T., \& Mombour, W. (1998). The modern assessment of personality disorders. Psychopathology, 31, 293-301.

Burns, A. M., Erickson, D. H., \& Brenner, C. A. (2014). Cognitive-behavioral therapy for medication-resistant psychosis: a meta-analytic review. Psychiatric Services, 65, 874-880. Bushman, B. J., \& Baumeister, R. F. (1998). Threatened egotism, narcissism, self-esteem, and direct and displaced aggression: does self-love or self-hate lead to violence? Journal of Personality and Social Psychology, 75, 219-229.

Cale, E. M., \& Lilienfeld, S. O. (2002). Sex differences in psychopathy and antisocial personality disorder: A review and integration. Clinical Psychology Review, 22, 1179-1207.

Carlson, E. N. (2013). Honestly arrogant or simply misunderstood? Narcissists' awareness of their narcissism. Self and Identity, 12, 259-277. 
Personality Disorders: Scientific Status

Chemerinski, E., Triebwasser, J., Roussos, P., \& Siever, L. J. (2013). Schizotypal personality disorder. Journal of Personality Disorders, 27, 652-679.

Chmielewski, M., Bagby, R. M., Markon, K., Ring, A. J., \& Ryder, A. G. (2014). Openness to experience, intellect, schizotypal personality disorder, and psychoticism: resolving the controversy. Journal of Personality Disorders, 28, 483-499.

Chmielewski, P. M., Fernandes, L. O., Yee, C. M., \& Miller, G. A. (1995). Ethnicity and gender in scales of psychosis proneness and mood disorders. Journal of Abnormal Psychology, 10, 464470.

Church, A. T. (1994). Relating the Tellegen and five-factor models of personality structure. Journal of Personality and Social Psychology, 67, 898-909.

Clark, L. A. (2005a). Stability and change in personality pathology: Revelations of three longitudinal studies. Journal of personality disorders, 19(5), 524-532.

Clark, L. A. (2005b). Temperament as a unifying basis for personality and psychopathology. Journal of Abnormal Psychology, 114, 505-521.

Clark, L. A. (2007). Assessment and diagnosis of personality disorder: Perennial issues and an emerging reconceptualization. Annual Review of Psychology, 58, 227-257.

Clark, L. A. (2009). Stability and change in personality disorder. Current Directions in Psychological Science, 18, 27-31.

Clarkin, J. F., Levy, K. N., Lenzenweger, M. F., \& Kernberg, O. F. (2007). Evaluating three treatments for borderline personality disorder: a multiwave study. American Journal of Psychiatry, 164, 922-928.

Clark, L.A., Livesley, W. J., \& Morey, L. (1997). Personality disorder assessment: The challenge of construct validity. Journal of Personality Disorders, 11, 205-231.

Cleckley, H. (1941). The mask of sanity: St. Louis: Mosby.

Coccaro, E. F. (2015). Intermittent explosive disorder. Psychiatric Times, 32(3), 47-47. 
Personality Disorders: Scientific Status

Coles, M. E., Pinto, A., Mancebo, M. C., Rasmussen, S. A., \& Eisen, J. L. (2008). OCD with comorbid OCPD: a subtype of OCD? Journal of Psychiatric Research, 42, 289-296.

Cooke, D. J. (1996). Psychopathic personality in different cultures: What do we know? What do we need to find out? Journal of Personality Disorders, 10, 23-40.

Cooper, R., \& Blashfield, R. K. (2016). Re-evaluating DSM-I. Psychological Medicine, 46, 449456.

Cooper, A. F., Kay, D. W. K., Curry, A. R., Garside, R. F., \& Roth, M. (1974). Hearing loss in paranoid and affective psychoses of the elderly. The Lancet, 304, 851-854.

Costa, P. T., Jr., \& McCrae, R. R. (1992). NEO PI-R professional manual. Odessa, FL: Psychological Assessment Resources, Inc.

Cramer, V., Torgersen, S., \& Kringlen, E. (2006). Personality disorders and quality of life: A population study. Comprehensive Psychiatry, 47, 178-184.

Crowell, S. E., Beauchaine, T. P., \& Linehan, M. M. (2009). A biosocial developmental model of borderline personality: Elaborating and extending Linehan's theory. Psychological Bulletin, 135, 495-510.

Cuthbert, B. N., \& Insel, T. R. (2013). Toward the future of psychiatric diagnosis: the seven pillars of RDoC. BMC Medicine, 11(1), 1.

De Bolle, M., Beyers, W., De Clercq, B., \& De Fruyt, F. (2012). General personality and psychopathology in referred and nonreferred children and adolescents: An investigation of continuity, pathoplasty, and complication models. Journal of Abnormal Psychology, 121, $958=970$.

Deltito, J. A., \& Stam, M. (1989). Psychopharmacological treatment of avoidant personality disorder. Comprehensive Psychiatry, 30, 498-504.

Dickinson, K. A., \& Pincus, A. L. (2003). Interpersonal analysis of grandiose and vulnerable narcissism. Journal of Personality Disorders, 17, 188-207. 
Personality Disorders: Scientific Status

Dickman, S. J. (1990). Functional and dysfunctional impulsivity: personality and cognitive correlates. Journal of Personality and Social Psychology, 58, 95-102.

Diggle, J. (2004). Theophrastus: Characters. Cambridge, U.K: Cambridge University Press.

DiLalla, L. F., \& Gottesman, I. I. (1991). Biological and genetic contributors to violence: Widom's untold tale. Psychological Bulletin, 109, 125-129.

Double, D. B. (1990). What would Adolf Meyer have thought of the neo-Kraepelinian approach? The Psychiatrist, 14, 472-474.

Edens, J. F., Marcus, D. K., Lilienfeld, S. O., \& Poythress Jr, N. G. (2006). Psychopathic, not psychopath: taxometric evidence for the dimensional structure of psychopathy. Journal of Abnormal Psychology, 115, 131-144.

Farmer, A. E., McGuffin, P., \& Gottesman, I. I. (1987). Twin concordance for DSM-III schizophrenia: scrutinizing the validity of the definition. Archives of General Psychiatry, 44, 634641.

Few, L. R., Miller, J. D., Rothbaum, A. O., Meller, S., Maples, J., Terry, D. P., ... \& MacKillop, J. (2013). Examination of the Section III DSM-5 diagnostic system for personality disorders in an outpatient clinical sample. Journal of Abnormal Psychology, 122, 1057-1069.

Fiedler, E. R., Oltmanns, T. F., \& Turkheimer, E. (2004). Traits associated with personality disorders and adjustment to military life: Predictive validity of self and peer reports. Military Medicine, 169, 207-211.

Fowler, K.A., O'Donohue, W., Lilienfeld, S.O. (2007). Introduction: Personality disorders in perspective. In O'Donohue, W.T., Fowler, K.A., \& Lilienfeld, S.O. (Eds.). Personality Disorders: Toward the DSM V. Thousand Oaks, CA: Sage Publications.

Frances, A. (1993). Dimensional diagnosis of personality--not whether, but when and which. Psychological Inquiry, 4, 110-111.

Frances, A. J., \& Widiger, T. (2012). Psychiatric diagnosis: Lessons from the DSM-IV past and cautions for the DSM-5 future. Annual Review of Clinical Psychology, 8, 109-130. 
Personality Disorders: Scientific Status

Freud, S. (1908), Character and anal eroticism. In J. Strachey (translator), The complete psychological works of Sigmund Freud, Vol. 9, James Strachey (translator), London: Hogarth. Frick, P. J., Ray, J. V., Thornton, L. C., \& Kahn, R. E. (2014). Can callous-unemotional traits enhance the understanding, diagnosis, and treatment of serious conduct problems in children and adolescents? A comprehensive review. Psychological Bulletin, 140, 1-57.

Gaughan, E. T., Miller, J. D., Pryor, L. R., \& Lynam, D. R. (2009). Comparing two alternative measures of general personality in the assessment of psychopathy: A test of the NEO PI-R and the MPQ. Journal of Personality, 77, 965-996.

Gough, H. G. (1965). Conceptual analysis of psychological test scores and other diagnostic variables. Journal of Abnormal Psychology, 70, 294-302.

Grove, W. M., \& Tellegen, A. (1991). Problems in the classification of personality disorders. Journal of Personality Disorders, 5, 31-41.

Hare, R.D. (1991/2003). The Hare Psychopathy Checklist-Revised. Toronto,CA: Multihealth Systems.

Harkness, A. R., \& Lilienfeld, S. O. (1997). Individual differences science for treatment planning: Personality traits. Psychological Assessment, 9, 349-360.

Harkness, A. R., Reynolds, S. M., \& Lilienfeld, S. O. (2014). A review of systems for psychology and psychiatry: adaptive systems, personality psychopathology five (PSY-5), and the DSM-5. Journal of Personality Assessment, 96, 121-139.

Harris, G. T., Rice, M. E., \& Quinsey, V. L. (1994). Psychopathy as a taxon: evidence that psychopaths are a discrete class. Journal of Consulting and Clinical Psychology, 62, 387-397. Haslam, N., Holland, E., \& Kuppens, P. (2012). Categories versus dimensions in personality and psychopathology: a quantitative review of taxometric research. Psychological Medicine, 42, 903-920.

Head, S. B., Baker, J. D., \& Williamson, D. A. (1991). Family environment characteristics and dependent personality disorder. Journal of Personality Disorders, 5, 256-263. 
Personality Disorders: Scientific Status Herbert, J.D. (2007). Avoidant personality disorder. In W.T. O'Donohue, K.A. Fowler, \& S.O. Lilienfeld (Eds.). Personality Disorders: Toward the DSM V (pp. 279-305). Thousand Oaks: Sage Publications.

Herbert, J. D., Hope, D. A., \& Bellack, A. S. (1992). Validity of the distinction between generalized social phobia and avoidant personality disorder. Journal of Abnormal Psychology, $101,332-339$.

Hewitt, P. L., \& Flett, G. L. (2007). When does conscientiousness become perfectionism? Traits, self-presentation styles, and cognitions suggest a persistent psychopathology. Current Psychiatry, 6, 49-60.

Hirschfeld, R. M. (1993). Personality disorders: Definition and diagnosis. Journal of Personality Disorders, 1, 9-17.

Hopwood, C. J., Wright, A. G., Ansell, E. B., \& Pincus, A. L. (2013). The interpersonal core of personality pathology. Journal of Personality Disorders, 27, 270-285.

Hyman, S. E. (2010). The diagnosis of mental disorders: the problem of reification. Annual Review of Clinical Psychology, 6, 155-179.

Jaffee, S. R., Caspi, A., Moffitt, T. E., \& Taylor, A. (2004). Physical maltreatment victim to antisocial child: evidence of an environmentally mediated process. Journal of Abnormal Psychology, 113, 44-55.

Jauhar, S., McKenna, P. J., Radua, J., Fung, E., Salvador, R., \& Laws, K. R. (2014). Cognitivebehavioural therapy for the symptoms of schizophrenia: systematic review and meta-analysis with examination of potential bias. The British Journal of Psychiatry, 204, 20-29.

Karpman, B. (1941). On the need of separating psychopathy into two distinct clinical types: the symptomatic and the idiopathic. Journal of Criminal Psychopathology, 3, 112-137.

Kelsoe, J. R. (2003). Arguments for the genetic basis of the bipolar spectrum. Journal of Affective Disorders, 73, 183-197. 
Personality Disorders: Scientific Status

Kendell, R. E. (2002). The distinction between personality disorder and mental illness. The British Journal of Psychiatry, 180, 110-115.

Kendler, K. S., \& Gruenberg, A. M. (1984). An independent analysis of the Danish adoption study of schizophrenia: VI. The relationship between psychiatric disorders as defined by DSM-III in the relatives and adoptees. Archives of General Psychiatry, 41, 555-564.

Kendler, K. S., McGuire, M., Gruenberg, A. M., O’Hare, A., Spellman, M., \& Walsh, D. (1993).

The Roscommon Family Study. III. Schizophrenia-related personality disorders in relatives. Archives of General Psychiatry, 50, 781-788.

Kendler, K. S., Myers, J., Torgersen, S.,Neale, M. C., \& Reichborn-Kjennerud, T. (2007). The heritability of cluster A personality disorders assessed by both personal interview and questionnaire. Psychological Medicine, 37, 655-665.

Kendler, K. S., Neale, M.C., \& Walsh, D. (1995). Evaluating the spectrum concept of schizophrenia. American Journal of Psychiatry, 152, 749-754.

Kernberg, O. (1967). Borderline personality organization. Journal of the American Psychoanalytic Association, 15, 641-685.

Kiesler, D. J. (1983). The 1982 Interpersonal Circle: A taxonomy for complementarity in human transactions. Psychological Review, 90, 185-214.

Kliem, S., Kröger, C., \& Kosfelder, J. (2010). Dialectical behavior therapy for borderline personality disorder: a meta-analysis using mixed-effects modeling. Journal of Consulting and Clinical Psychology, 78(6), 936=951.

Klein, D. N., Kotov, R., \& Bufferd, S. J. (2011). Personality and depression: explanatory models and review of the evidence. Annual Review of Clinical Psychology, 7, 269-295.

Klonsky, E. D. (2000). The DSM classification of personality disorder: Clinical wisdom or empirical truth? A response to Alvin R. Mahrer's problem. Journal of Clinical Psychology, 56, 1615-1621. 
Personality Disorders: Scientific Status

Klonsky, E. D., \& Oltmanns, T. F. (2002). Informant-reports of personality disorder: Relation to self-reports and future research directions. Clinical Psychology: Science and Practice, 9, 300311.

Knappich, M., Hörz-Sagstetter, S., Schwerthöffer, D., Leucht, S., \& Rentrop, M. (2014).

Pharmacotherapy in the treatment of patients with borderline personality disorder: results of a survey among psychiatrists in private practices. International Clinical Psychopharmacology, 29, 224-228.

Koenigsberg, H., Reynolds Goodman, M., New, A., Mitropoulou, V., Trestman, R., Silverman, et al. (2003). Risperidone in the treatment of schizotypal personality disorder. Journal of Clinical Psychiatry, 64, 628-634.

Kohut, H. (1966). Forms and transformations of narcissism. Journal of the American Psychoanalytic Association, 14, 243-272.

Konrath, S., Meier, B. P., \& Bushman, B. J. (2014). Development and validation of the single item narcissism scale (SINS). PloS One, 9(8), e103469.

Kremers, I. P., Spinhoven, P., Van der Does, A. J. W., \& Van Dyck, R. (2006). Social problem solving, autobiographical memory and future specificity in outpatients with borderline personality disorder. Clinical Psychology \& Psychotherapy, 13, 131-137.

Kroll, J., Sines, L., Martin, K., Lari, S., Pyle, R., \& Zander, J. (1981). Borderline personality disorder: Construct validity of the concept. Archives of General Psychiatry, 38, 1021-1026. Krueger, R. F., \& Markon, K. E. (2014). The role of the DSM-5 personality trait model in moving toward a quantitative and empirically based approach to classifying personality and psychopathology. Annual Review of Psychology, 10, 477-501.

Lahey, B. B. (2014). What we need to know about callous-unemotional traits: comment on Frick, Ray, Thornton, and Kahn (2014). Psychological Bulletin, 140, 58-63. 
Personality Disorders: Scientific Status

Latzman, R. D., \& Hopkins, W. D. (2016). Letter to the Editor: Avoiding a lost opportunity for psychological medicine: importance of chimpanzee research to the National Institutes of Health portfolio. Psychological Medicine, 46, 2445-2447.

Latzman, R. D., Lilienfeld, S. O, Latzman, N. E., \& Clark, L. A. (2013). Exploring callous and unemotional traits in youth via trait personality: An eye toward DSM-5. Personality Disorders: Theory, Research, and Treatment, 4, 191-202.

Lazarus, S. A., Cheavens, J. S., Festa, F., \& Rosenthal, M. Z. (2014). Interpersonal functioning in borderline personality disorder: A systematic review of behavioral and laboratory-based assessments. Clinical Psychology Review, 34, 193-205.

Leary, T. (1957). Interpersonal diagnosis of personality: A functional theory and methodology for personality evaluation. New York: Wiley.

Lenzenweger, M. F. (1999). Stability and change in personality disorder features: The Longitudinal Study of Personality Disorders. Archives of General Psychiatry, 56, 1009-1015. Lenzenweger, M. F., McLachlan, G., \& Rubin, D. B. (2007). Resolving the latent structure of schizophrenia endophenotypes using expectation-maximization-based finite mixture modeling. Journal of Abnormal Psychology, 116, 16-29.

Levy. K.N., Reynoso, J. S., Wasserman, R.H., Clarkin, J.F. (2007). Narcissistic personality disorder. In W.T. O'Donohue, K.A. Fowler, \& S.O. Lilienfeld (Eds.). Personality Disorders: Toward the DSM V (pp. 233-277). Thousand Oaks: Sage Publications Lieb, K., Zanarini, M. C., Schmahl, C., Linehan, M. M., \& Bohus, M. (2004). Borderline personality disorder. The Lancet, 364, 453-461.

Lilienfeld, S. O. (1994). Conceptual problems in the assessment of psychopathy. Clinical Psychology Review, 14, 17-38.

Lilienfeld, S. O. (2014). The Research Domain Criteria (RDoC): An analysis of methodological and conceptual challenges. Behaviour Research and Therapy, 62, 129-139. 
Personality Disorders: Scientific Status

Lilienfeld, S.O. \& Arkowitz, H. (2012, January 1). Diagnosis of borderline personality disorder is often flawed. Scientific American Mind. http://www.scientificamerican.com/article/the-truthabout-borderline/

Lilienfeld, S. O., Patrick, C. J., Benning, S. D., Berg, J., Sellbom, M., \& Edens, J. F. (2012). The role of fearless dominance in psychopathy: Confusions, controversies, and clarifications.

Personality Disorders: Theory, Treatment, and Research, 33, 327-340.

Lilienfeld, S. O., Sauvigné, K. C., Lynn, S. J., Cautin, R. L., Latzman, R. D., \& Waldman, I. D. (2015). Fifty psychological and psychiatric terms to avoid: a list of inaccurate, misleading, misused, ambiguous, and logically confused words and phrases. Frontiers in psychology, 6. Lilienfeld, S. O., Smith, S. F., Sauvigne, K. C., Patrick, C. J., Drislane, L. E., Latzman, R. D., \& Krueger, R. F. (in press). Is boldness relevant to psychopathic personality? Meta-analytic relations with non-psychopathy checklist-based measures of psychopathy. Psychological Assessment.

Lilienfeld, S.O., Smith, S.F. \& Watts, A.L. (2016). Diagnosis: Conceptual issues and controversies (waiting page numbers). In W.E Craighead, D.J., Miklowitz, \& L.W. Craighead, Psychopathology: History, diagnosis, and empirical foundations (3rd edition). New York: Wiley. Lilienfeld, S. O., \& Treadway, M. T. (2016). Clashing diagnostic approaches: DSM-ICD versus RDoC. Annual Review of Clinical Psychology, 12, 435-463.

Lilienfeld, S. O., Van Valkenburg, C., Larntz, K., \& Akiskal, H. S. (1986). The relationship of histrionic personality disorder to antisocial personality and somatization disorders. American Journal of Psychiatry, 143, 718-722.

Lilienfeld, S. O., Watts, A. L., Francis Smith, S., Berg, J. M., \& Latzman, R. D. (2015). Psychopathy deconstructed and reconstructed: Identifying and assembling the Personality building blocks of Cleckley's chimera. Journal of Personality, 83, 593-610.

Linehan, M. M. (1987). Dialectical behavior therapy for borderline personality disorder: Theory and method. Bulletin of the Menninger Clinic, 51, 261-276. 
Personality Disorders: Scientific Status

Livesley, W. J. (2000). Introduction to Special Feature. Journal of Personality Disorders, 14, 1-2.

Lobbestael, J., Leurgans, M., \& Arntz, A. (2011). Inter-rater reliability of the Structured Clinical Interview for DSM-IV Axis I disorders (SCID I) and Axis II disorders (SCID II). Clinical Psychology \& Psychotherapy, 18, 75-79.

Luntz, B. K., \& Widom, C. S. (1994). Antisocial personality disorder in abused and neglected children grown up. American Journal of Psychiatry, 151, 670-674.

Lykken, D.T. (1995). The antisocial personalities. Hillsdale, N.J.: Erlbaum.

Lynam, D. R., \& Widiger, T. A. (2001). Using the five-factor model to represent the DSM-IV personality disorders: an expert consensus approach. Journal of Abnormal Psychology, 110, 401-412.

Magill, C. A. (2004). The boundary between borderline personality disorder and bipolar disorder: current concepts and challenges. Canadian Journal of Psychiatry, 49, 551-556.

Maj, M. (2005). 'Psychiatric comorbidity': an artefact of current diagnostic systems? The British Journal of Psychiatry, 186, 182-184.

Markon, K. E., Chmielewski, M., \& Miller, C. J. (2011). The reliability and validity of discrete and continuous measures of psychopathology: A quantitative review. Psychological Bulletin, 137, 856-879.

Markon, K. E., Krueger, R. F., \& Watson, D. (2005). Delineating the structure of normal and abnormal personality: an integrative hierarchical approach. Journal of Personality and Social Psychology, 88, 139-157. Matsunaga, H., Kiriike, N., Matsui, T., Oya, K., Iwasaki, Y., Koshimune, K., ... \& Stein, D. J. (2002). Obsessive-compulsive disorder with poor insight. Comprehensive Psychiatry, 43, 150-157.

McCrae, R. R., \& Costa, P. T. (1987). Validation of the five-factor model of personality across instruments and observers. Journal of Personality and Social Psychology, 52, 81-90. 
Personality Disorders: Scientific Status

McCrae, R. R., \& Costa, P. T. (1995). Trait explanations in personality psychology. European Journal of Personality, 9, 231-252.

McLemore, C. W., \& Benjamin, L. S. (1979). Whatever happened to interpersonal diagnosis? A psychosocial alternative to DSM-III. American Psychologist, 34, 17-34.

Meehl, P. E. (1962). Schizotaxia, schizotypy, schizophrenia. American Psychologist, 17, 827838.

Meehl, P. E. (1990). Toward an integrated theory of schizotaxia, schizotypy, and schizophrenia. Journal of Personality Disorders, 4, 1-99.

Meehl, P. E., \& Golden, R. (1982). Taxometric methods. In P. Kendall \& J.N. Butcher (Eds.), Handbook of research methods in clinical psychology (pp. 127-181). New York: Wiley.

Mier, D., Lis, S., Esslinger, C., Sauer, C., Hagenhoff, M., Ulferts, J., ... \& Kirsch, P. (2013). Neuronal correlates of social cognition in borderline personality disorder. Social Cognitive and Affective Neuroscience, 8, 531-537.

Miller, J. D., Campbell, W. K., \& Pilkonis, P. A. (2007). Narcissistic personality disorder: Relations with distress and functional impairment. Comprehensive Psychiatry, 48, 170-177. Miller, J. D., Dir, A., Gentile, B., Wilson, L., Pryor, L. R., \& Campbell, W. K. (2010). Searching for a vulnerable dark triad: Comparing factor 2 psychopathy, vulnerable narcissism, and borderline personality disorder. Journal of Personality, 78, 1529-1564.

Miller, J. D., Gentile, B., Wilson, L., \& Campbell, W. K. (2013). Grandiose and vulnerable narcissism and the DSM-5 pathological personality trait model. Journal of Personality Assessment, 95, 284-290.

Miller, J. D., Hoffman, B. J., Gaughan, E. T., Gentile, B., Maples, J., \& Campbell, W.K. (2011). Grandiose and vulnerable narcissism: A nomological network analysis. Journal of Personality, 79, 1013-1042. 
Personality Disorders: Scientific Status

Miller, J. D., Jones, S. E., \& Lynam, D. R. (2011). Psychopathic traits from the perspective of self and informant reports: Is there evidence for a lack of insight? Journal of Abnormal Psychology, 120, 758-764.

Miller, J. D., \& Lynam, D. R. (2012). An examination of the Psychopathic Personality Inventory's nomological network: a meta-analytic review. Personality Disorders: Theory, Research, and Treatment, 3, 305-326.

Miller, J. D., \& Lynam, D. R. (2013). Missed opportunities in the DSM-5 Section III personality disorder model: Commentary on "Personality disorders are the vanguard of the post-DSM-5.0 era." Personality Disorders: Theory, Treatment, and Research, 4, 365-366.

Miller, J. D., Widiger, T. A., \& Campbell, W. K. (2010). Narcissistic personality disorder and the DSM-V. Journal of Abnormal Psychology, 119, 640-649.

Millon, T. (1969). Modern psychopathology: A biosocial approach to maladaptive learning and functioning. Philadelphia, PA; Saunders.

Mittal, V.A., Kalus, O., Bernstein, D.P., Siever, L.J. (2007). Schizoid personality disorder. In W.T. O'Donohue, K.A. Fowler, \& S.O. Lilienfeld (Eds.). Personality Disorders: Toward the DSM $V($ pp. 63-81). Thousand Oaks: Sage Publications

Morey, L. C., Benson, K. T., \& Skodol, A. E. (2016). Relating DSM-5 section III personality traits to section II personality disorder diagnoses. Psychological Medicine, 46, 647-655.

Mudrack, P. E. (2004). Job involvement, obsessive-compulsive personality traits, and workaholic behavioral tendencies. Journal of Organizational Change Management, 17, 490-508. Newcomb, T. (1931). An experiment designed to test the validity of a rating technique. Journal of Educational Psychology, 22, 279-289.

Newhill, C. E. (1990). The role of culture in the development of paranoid symptomatology. American Journal of Orthopsychiatry, 60, 176-185.

O'Donohue, W., Fowler, K. A., \& Lilienfeld, S. O. (Eds.). (2007). Personality disorders: Toward the DSM-V. New York: Sage Publications. 
Oldham, J. M. (2015). Personality disorders. Focus, 3, 372-382.

Oldham, J. M., \& Rosnick, L. (1990). Validity of the Personality Diagnostic QuestionnaireRevised: comparison with two structured interviews. American Journal of Psychiatry, 147, 10431048.

Oldham, J. M., Skodol, A. E., Kellman, H. D., Hyler, S. E., Rosnick, L., \& Davies, M. (1992). Diagnosis of DSM-III-R personality disorders by two semistructured interviews: Patterns of comorbidity. American Journal of Psychiatry, 149, 213-220.

Oltmanns, T. F., Rodrigues, M. M., Weinstein, Y., \& Gleason, M. E. (2014). Prevalence of personality disorders at midlife in a community sample: Disorders and symptoms reflected in interview, self, and informant reports. Journal of Psychopathology and Behavioral Assessment, $36,177-188$.

Oltmanns, T. F., \& Turkheimer, E. (2009). Person perception and personality pathology. Current Directions in Psychological Science, 18, 32-36.

Pap, A. (1953). Reduction-sentences and open concepts. Methodos, 5, 3-30.

Paris, J., \& Zweig-Frank, H. (2001). A 27-year follow-up of patients with borderline personality disorder. Comprehensive Psychiatry, 42, 482-487.

Patterson, C. M., \& Newman, J. P. (1993). Reflectivity and learning from aversive events: toward a psychological mechanism for the syndromes of disinhibition. Psychological Review, $100,716-736$.

Plakun, E.M. (1989). Narcissistic personality disorder: A validity study and comparison to borderline personality disorder. Psychiatric Clinics of North America, 12, 603-620.

Pope, H. G., Jonas, J. M., Hudson, J. I., Cohen, B. M., \& Gunderson, J. G. (1983). The validity of DSM-III borderline personality disorder: a phenomenologic, family history, treatment response, and long-term follow-up study. Archives of General Psychiatry, 40, 23-30. 
Personality Disorders: Scientific Status

Poythress, N. G., Edens, J. F., Skeem, J. L., Lilienfeld, S. O., Douglas, K. S., Frick, P. J., ... \& Wang, T. (2010). Identifying subtypes among offenders with antisocial personality disorder: a cluster-analytic study. Journal of Abnormal Psychology, 119, 389-400.

Rado, S. (1956). Psychoanalysis of behavior. New York: Grune and Stratton.

Raine, A. (1992). Sex differences in schizotypal personality in a nonclinical population. Journal of Abnormal Psychology, 101, 361-364.

Raine, A. (2006). Schizotypal personality: neurodevelopmental and psychosocial trajectories. Annual Review of Clinical Psychology, 2, 291-326.

Rawlings, D., Williams, B., Haslam, N., \& Claridge, G. (2008). Taxometric analysis supports a dimensional latent structure for schizotypy. Personality and Individual Differences, 44, 16401651.

Reich, J., Noyes Jr, R., \& Troughton, E. (1987). Dependent personality disorder associated with phobic avoidance in patients with panic disorder. American Journal of Psychiatry, 144, 323-326. Reichborn-Kjennerud, T., Czajkowski, N., Torgersen, S., Neale, M. C., Ørstavik, R. E., Tambs, K., \& Kendler, K. S. (2007). The relationship between avoidant personality disorder and social phobia: a population-based twin study. American Journal of Psychiatry, 164, 1722-1728. Reichenberg, A., Rieckmann, N., \& Harvey, P. D. (2005). Stability in schizophrenia symptoms over time: findings from the Mount Sinai Pilgrim Psychiatric Center Longitudinal Study. Journal of Abnormal Psychology, 114, 363-372.

Rhee, S. H., \& Waldman, I. D. (2002). Genetic and environmental influences on antisocial behavior: a meta-analysis of twin and adoption studies. Psychological Bulletin, 128, 490-529. Ro, E., \& Clark, L. A. (2013). Interrelations between psychosocial functioning and adaptive-and maladaptive-range personality traits. Journal of Abnormal Psychology, 122, 822-835.

Robins, L.N. (1966). Deviant children grown up. A sociological and psychiatric study of sociopathic personality. Baltimore, MD.: William \& Wilkins Company. 
Personality Disorders: Scientific Status

Rohde, P., Lewinsohn, P. M., \& Seeley, J. R. (1990). Are people changed by the experience of having an episode of depression? A further test of the scar hypothesis. Journal of Abnormal Psychology, 99, 264-271.

Roberts, B. W., \& DelVecchio, W. F. (2000). The rank-order consistency of personality traits from childhood to old age: a quantitative review of longitudinal studies. Psychological Bulletin, 126, 3-35.

Roberts, B. W., Walton, K. E., \& Viechtbauer, W. (2006). Patterns of mean-level change in personality traits across the life course: a meta-analysis of longitudinal studies. Psychological Bulletin, 132, 1-25.

Ronningstam, E. (1996). Pathological narcissism and narcissistic personality disorder in Axis I disorders. Harvard Review of Psychiatry, 3, 326-340.

Rosenthal, M. Z., Gratz, K. L., Kosson, D. S., Cheavens, J. S., Lejuez, C. W., \& Lynch, T. R. (2008). Borderline personality disorder and emotional responding: A review of the research literature. Clinical Psychology Review, 28, 75-91.

Sacco, J. M., \& Olczak, P. V. (1996). Personality and cognition: Obsessivity, hystericism, and some correlates. Journal of Social Behavior and Personality, 11, 165-176.

Salekin, R. T. (2002). Psychopathy and therapeutic pessimism: Clinical lore or clinical reality?. Clinical Psychology Review, 22, 79-112.

Samuel, D.S., Suzuki, T., \& Griffin, S.A. (in press). Clinicians and clients disagree: Five implications for clinical science. Journal of Abnormal Psychology.

Samuel, D. B., \& Widiger, T. A. (2008). A meta-analytic review of the relationships between the five-factor model and DSM-IV-TR personality disorders: A facet level analysis. Clinical Psychology Review, 28(8), 1326-1342.

Sanislow, C. A., Pine, D. S., Quinn, K. J., Kozak, M. J., Garvey, M. A., Heinssen, R. K., ... \& Cuthbert, B. N. (2010). Developing constructs for psychopathology research: research domain criteria. Journal of Abnormal Psychology, 119, 631-639. 
Personality Disorders: Scientific Status

Saulsman, L. M., \& Page, A. C. (2004). The five-factor model and personality disorder empirical literature: A meta-analytic review. Clinical Psychology Review, 23, 1055-1085.

Schmideberg M. (1959). In S. Arieti (Ed.), The borderline patient (pp. 398-416). Vol. 1. New York: Basic Books.

Basic Shapiro, D. (1965). Neurotic styles. New York: Basic Books.

Shedler, J., Beck, A., Fonagy, P., Gabbard, G. O., Gunderson, J., Kernberg, O., ... \& Westen, D. (2010). Personality disorders in DSM-5. American Journal of Psychiatry, 167, 1026-1028.

Sher, K. J., \& Trull, T. J. (1994). Personality and disinhibitory psychopathology: alcoholism and antisocial personality disorder. Journal of Abnormal Psychology, 103, 92-102.

Shmueli, G. (2010). To explain or to predict? Statistical Science, 25, 289-310.

Shea M.T (1995). Interrelationships among categories of personality disorders. In W.J. Livesley (Ed.), The DSM-IV personality disorders: Diagnosis and treatment of mental disorders (pp. 397406). New York; Guilford.

Skeem, J. L., Polaschek, D. L., Patrick, C. J., \& Lilienfeld, S. O. (2011). Psychopathic personality bridging the gap between scientific evidence and public policy. Psychological Science in the Public Interest, 12, 95-162.

Skodol, A. E. (2012). Personality disorders in DSM-5. Annual review of Clinical Psychology, 8, 317-344.

Skodol, A. E., Gunderson, J. G., McGlashan, T. H., Dyck, I. R., Stout, R. L., Bender, D. S., ... \& Sanislow, C. A. (2002). Functional impairment in patients with schizotypal, borderline, avoidant, or obsessive-compulsive personality disorder. American Journal of Psychiatry, 159, $276-283$. Smith. S.F., \& Lilienfeld. (2012). Histrionic personality disorder. In V. Ramachandran (Ed.), Encyclopedia of human behavior, Volume 3 (pp. 312-315). New York: Wiley.

Smith, S. F., \& Lilienfeld, S. O. (2015). The response modulation hypothesis of psychopathy: A meta-analytic and narrative analysis. Psychological Bulletin, 141, 1145-1177. 
Personality Disorders: Scientific Status

Snyder, M., \& Gangestad, S. (1986). On the nature of self-monitoring: matters of assessment, matters of validity. Journal of Personality and Social Psychology, 51, 125-139.

Standage, K. F. (1979). The use of Schneider's typology for the diagnosis of personality disorders--an examination of reliability. The British Journal of Psychiatry, 135, 238-242. Stern, A. (1938). Borderline group of neuroses. The Psychoanalytic Quarterly, 7. 467-489. Stinson, F. S., Dawson, D. A., Goldstein, R. B., Chou, S. P., Huang, B., Smith, S. M., ... \& Grant, B. F. (2008). Prevalence, correlates, disability, and comorbidity of DSM-IV narcissistic personality disorder: results from the wave 2 national epidemiologic survey on alcohol and related conditions. Journal of Clinical Psychiatry, 69, 1033-1045.

Sullivan, H. S. (2013). The interpersonal theory of psychiatry. New York: Routledge.

Swartz, M., Blazer, D., George, L., \& Winfield, I. (1990). Estimating the prevalence of borderline personality disorder in the community. Journal of Personality Disorders, 4, 257-272.

Teichman, J. (1985). The definition of person. Philosophy, 60, 175-185.

Tellegen, A. (1993). Folk concepts and psychological concepts of personality and personality disorder. Psychological Inquiry, 4, 122-130.

Tellegen, A. (in press). Multidimensional Personality Questionnaire. Minneapolis, MN: University of Minnesota Press.

Tellegen, A., \& Waller, N. G. (2008). Exploring personality through test construction: Development of the Multidimensional Personality Questionnaire. The SAGE Handbook of Personality Theory and Assessment, 2, 261-292.

Teusch, L., Böhme, H., Finke, J., \& Gastpar, M. (2001). Effects of client-centered psychotherapy for personality disorders alone and in combination with psychopharmacological treatment. Psychotherapy and Psychosomatics, 70, 328-336.

Tonkin, M., \& Fine, H. J. (1985). Narcissism and borderline states: Kernberg, Kohut, and psychotherapy. Psychoanalytic Psychology, 2, 221-239. 
Personality Disorders: Scientific Status

Tomko, R. L., Trull, T. J., Wood, P. K., \& Sher, K. J. (2014). Characteristics of borderline personality disorder in a community sample: comorbidity, treatment utilization, and general functioning. Journal of Personality Disorders, 28, 734-750.

Torgersen, S., Lygren, S., Øien, P. A., Skre, I., Onstad, S., Edvardsen, J., ... \& Kringlen, E. (2000). A twin study of personality disorders. Comprehensive Psychiatry, 41, 416-425.

Triebwasser, J., Chemerinski, E., Roussos, P., \& Siever, L. J. (2012). Schizoid personality disorder. Journal of Personality Disorders, 26, 919-926.

Triebwasser, J., Chemerinski, E., Roussos, P., \& Siever, L. J. (2013). Paranoid personality disorder. Journal of Personality Disorders, 27, 795-805.

Trobst, K. K., Ayearst, L. E., \& Salekin, R. T. (2013). Where is the personality in personality disorder assessment? A comparison across four sets of personality disorder scales. Multivariate Behavioral Research, 39, 231-271.

Trull, T. J., \& Durrett, C. A. (2005). Categorical and dimensional models of personality disorder. Annual Review of Clinical Psychology, 1, 355-380.

Trzesniewski, K.H. \& Donnellan, M.B. (2010) Rethinking "Generation Me”: A study of cohort effects from 1976-2006. Perspectives on Psychological Science, 5, 58-75.

Turner, S. M., Beidel, D. C., Dancu, C. V., \& Keys, D. J. (1986). Psychopathology of social phobia and comparison to avoidant personality disorder. Journal of Abnormal Psychology, 95, 389-394.

Twenge, J. M., Konrath, S., Foster, J. D., Campbell, W.K., \& Bushman, B. J. (2008). Egos inflating over time: A cross-temporal meta-analysis of the Narcissistic Personality Inventory. Journal of Personality, 76, 875-902.

Tyrer, P., Reed, G. M., \& Crawford, M. J. (2015). Classification, assessment, prevalence, and effect of personality disorder. The Lancet, 385, 717-726. 
Personality Disorders: Scientific Status Vaillant, G. E. (1992). The beginning of wisdom is never calling a patient a borderline; or, the clinical management of immature defenses in the treatment of individuals with personality disorders. The Journal of Psychotherapy Practice and Research, 1, 117-134.

Van Valkenburg, C., Kluznik, J. C., Speed, N., \& Akiskal, H. S. (2006). Cyclothymia and labile personality: Is all folie circulaire?. Journal of Affective Disorders, 96, 177-181.

Venables, N. C., Hall, J. R., \& Patrick, C. J. (2014). Differentiating psychopathy from antisocial personality disorder: A triarchic model perspective. Psychological Medicine, 44, 1005-1013. Verheul, R., \& Widiger, T. A. (2004). A meta-analysis of the prevalence and usage of the personality disorder not otherwise specified (PDNOS) diagnosis. Journal of Personality Disorders, 18, 309-319.

Watson, D., \& Clark, L. A. (1984). Negative affectivity: The disposition to experience aversive emotional states. Psychological Bulletin, 96, 465-490.

Watson, D., Clark, L. A., \& Harkness, A. R. (1994). Structures of personality and their relevance to psychopathology. Journal of Abnormal Psychology, 103, 18-31.

Weisz, J. R., Weiss, B., Alicke, M. D., \& Klotz, M. L. (1987). Effectiveness of psychotherapy with children and adolescents: A meta-analysis for clinicians. Journal of Consulting and Clinical Psychology, 55, 542-549.

Westen, D. (2012). Prototype diagnosis of psychiatric syndromes. World Psychiatry, 11, 16-21. Westen, D., \& Shedler, J. (2000). A prototype matching approach to diagnosing personality disorders: Toward DSM-V. Journal of Personality Disorders, 14, 109-126.

Wetzler, S., \& Morey, L. C. (1999). Passive-aggressive personality disorder: The demise of a syndrome. Psychiatry, 62, 49-59.

Whooley, O. (2014). Nosological reflections: The failure of DSM-5, the emergence of RDoC, and the cecontextualization of mental distress. Society and Mental Health, 2156869313519114. Widiger, T. A. (1993). The DSM-III-R categorical personality disorder diagnoses: A critique and an alternative. Psychological Inquiry, 4, 75-90. 
Personality Disorders: Scientific Status

Widiger, T. A. (2007). Alternatives to DSM-IV: Axis II. In W. O'Donohue, K. A. Fowler, \& S. O. Lilienfeld (Eds.), Personality disorders: Toward the DSM-V (pp. 21-40). Thousand Oaks, CA: Sage.

Widiger, T. A. (2011). Personality and psychopathology. World Psychiatry, 10, 103-106.

Widiger, T. A., \& Costa Jr, P. T. (1994). Personality and personality disorders. Journal of Abnormal Psychology, 103, 78-91.

Widiger, T. A., \& Frances, A. (1985). The DSM-III personality disorders: Perspectives from psychology. Archives of General Psychiatry, 42, 615-623.

Widiger, T. A., Frances, A. J., Pincus, H. A., Ross, R., First, M. B., \& Davis, W. W.

(Eds.). (1998). DSM-IV sourcebook (Vol. 4). Washington, DC: American Psychiatric

Press.

Widiger, T. A., Frances, A., Spitzer, R. L., \& Williams, J. B. (1988). The DSM-III-R personality disorders: An overview. American Journal of Psychiatry, 145, 786-795.

Widiger, T. A., \& Trull, T. J. (2007). Plate tectonics in the classification of personality disorder: Shifting to a dimensional model. American Psychologist, 62, 71-83.

Wiggins, J. S. (1979). A psychological taxonomy of trait-descriptive terms: The interpersonal domain. Journal of Personality and Social Psychology, 37, 395-412.

Wink, P. (1991). Two faces of narcissism. Journal of Personality and Social Psychology, 61, $590-597 /$

Zachar, P., Krueger, R. F., \& Kendler, K. S. (2016). Personality disorder in DSM-5: An oral history. Psychological Medicine, 46, 1-10.

Zimmerman, M. (2011). A critique of the proposed prototype rating system for personality disorders in DSM-5. Journal of Personality Disorders, 25, 206-221.

Zimmerman, M., \& Coryell, W. H. (1990). Diagnosing personality disorders in the community: A comparison of self-report and interview measures. Archives of General Psychiatry, 47, 527-531. 
Personality Disorders: Scientific Status

Zimmerman, M., \& Mattia, J. I. (1999a). Axis I diagnostic comorbidity and borderline personality disorder. Comprehensive Psychiatry, 40, 245-252.

Zimmerman, M., \& Mattia, J. I. (1999b). Psychiatric diagnosis in clinical practice: is comorbidity being missed? Comprehensive psychiatry, 40(3), 182-191.

Zuckerman, M. (1995). Behavioral expressions and biosocial bases of sensation seeking. New York: Cambridge University Press. 